\title{
An anomalous subauroral red arc on 4 August, 1972: comparison of ISIS-2 satellite data with numerical calculations
}

\author{
V. V. Lobzin, A. V. Pavlov, N. M. Pavlova \\ Institute of Terrestrial Magnetism, Ionosphere and Radio-Wave Propagation, Russian Academy of Science (IZMIRAN), \\ Troitsk, Moscow Region, 142092, Russia \\ E-mail: pavlov@charley.izmiran.rssi.ru
}

Received: 12 October 1998 / Revised: 24 June 1999 / Accepted: 7 July 1999

\begin{abstract}
This study compares the Isis II satellite measurements of the electron density and temperature, the integral airglow intensity and volume emission rate at $630 \mathrm{~nm}$ in the SAR arc region, observed at dusk on 4 August, 1972, in the Southern Hemisphere, during the main phase of the geomagnetic storm. The model results were obtained using the time dependent one-dimensional mathematical model of the Earth's ionosphere and plasmasphere (the IZMIRAN model). The major enhancement to the IZMIRAN model developed in this study to explain the two component $630 \mathrm{~nm}$ emission observed is the analytical yield spectrum approach to calculate the fluxes of precipitating electrons and the additional production rates of $\mathrm{N}_{2}^{+}, \mathrm{O}_{2}^{+}, \mathrm{O}^{+}\left({ }^{4} S\right), \mathrm{O}^{+}\left({ }^{2} D\right)$, $\mathrm{O}^{-}\left({ }^{2} P\right)$, and $\mathrm{O}^{+}\left({ }^{2} P\right)$ ions, and $\left.\mathrm{O}^{(} D\right)$ in the SAR arc regions in the Northern and Southern Hemispheres. In order to bring the measured and modelled electron temperatures into agreement, the additional heating electron rate of $1.05 \mathrm{eV} \mathrm{cm}^{-3} \mathrm{~s}^{-1}$ was added in the energy balance equation of electrons at altitudes above $5000 \mathrm{~km}$ during the main phase of the geomagnetic storm. This additional heating electron rate determines the thermally excited $630 \mathrm{~nm}$ emission observed. The IZMIRAN model calculates a $630 \mathrm{~nm}$ integral intensity above $350 \mathrm{~km}$ of $4.1 \mathrm{kR}$ and a total $630 \mathrm{~nm}$ integral intensity of $8.1 \mathrm{kR}$, values which are slightly lower compared to the observed $4.7 \mathrm{kR}$ and $10.6 \mathrm{kR}$. We conclude that the $630 \mathrm{~nm}$ emission observed can be explained considering both the soft energy electron excited component and the thermally excited component. It is found that the inclusion of $\mathrm{N}_{2}(v>0)$ and $\mathrm{O}_{2}(v>0)$ in the calculations of the $\mathrm{O}^{+}\left({ }^{4} S\right)$ loss rate improves the agreement between the calculated $\mathrm{N}_{\mathrm{e}}$ and the data on 4 August, 1972. The $\mathrm{N}_{2}(v>0)$ and $\mathrm{O}_{2}(v>0)$ effects are enough to explain the electron density depression in the SAR arc F-region and above F2 peak altitude. Our calculations show that the increase in the $\mathrm{O}^{+}+\mathrm{N}_{2}$ rate factor due to the vibratio-
\end{abstract}

Correspondence to: A. V. Pavlov nally excited nitrogen produces the $5-19 \%$ reductions in the calculated quiet daytime peak density and the 16$24 \%$ decrease in $\mathrm{NmF} 2$ in the SAR arc region. The increase in the $\mathrm{O}^{+}+\mathrm{N}_{2}$ loss rate due to vibrationally excited $\mathrm{O}_{2}$ produces the $7-26 \%$ decrease in the calculated quiet daytime peak density and the 12-26\% decrease in $\mathrm{NmF} 2$ in the SAR arc region. We evaluated the role of the electron cooling rates by low-lying electronic excitation of $\mathrm{O}_{2}\left(a^{1} \Delta_{g}\right)$ and $\mathrm{O}_{2}\left(b^{1} \Sigma_{g}^{+}\right)$, and rotational excitation of $\mathrm{O}_{2}$, and found that the effect of these cooling rates on $T_{e}$ can be considered negligible during the quiet and geomagnetic storm period 3-4 August, 1972. The energy exchange between electron and ion gases, the cooling rate in collisions of $\mathrm{O}\left({ }^{3} P\right)$ with thermal electrons with excitation of $\mathrm{O}\left({ }^{1} D\right)$, and the electron cooling rates by vibrational excitation of $\mathrm{O}_{2}$ and $\mathrm{N}_{2}$ are the largest cooling rates above $200 \mathrm{~km}$ in the SAR arc region on 4 August, 1972. The enhanced IZMIRAN model calculates also number densities of $\mathrm{N}_{2}\left(B^{3} \Pi_{g}^{+}\right), \mathrm{N}_{2}\left(C^{3} \Pi_{u}\right)$, and $\mathrm{N}_{2}\left(A^{3} \Sigma_{u}^{+}\right)$at several vibrational levels, $\mathrm{O}\left({ }^{1} S\right)$, and the volume emission rate and integral intensity at $557.7 \mathrm{~nm}$ in the region between 120 and $1000 \mathrm{~km}$. We found from the model that the integral intensity at $557.7 \mathrm{~nm}$ is much less than the integral intensity at $630 \mathrm{~nm}$.

Key words. Atmospheric composition and structure (airglow and aurora; thermosphere - composition and chemistry) - Ionosphere (ionosphere - magnetosphere interactions)

\section{Introduction}

The characteristic spectral emissions at $630 \mathrm{~nm}$ that identify stable auroral red (SAR) arcs are observed optically on the equatorward edge of the mid-latitude ionospheric trough in both the Northern and Southern Hemispheres on approximately the same $L$ shell value of 
the geomagnetic field during large magnetic storms characterised by geomagnetic planetary index $K_{p}$ of 5 or greater (Rees and Roble, 1975; Kozyra et al., 1997). A major part of ground and satellite observations that determine the properties of the SAR arcs have been obtained in the Northern Hemisphere. The observed SAR arc properties in magnetically conjugate hemispheres were discussed only by Reed and Blamont (1968), who determined the positions of the SAR arcs on 28-29 September, 1967, using data from the satellite Ogo 4, and LaValle and Elliot (1972), who presented and discussed OV1-10 satellite data on 16 February, 1967, and Pavlov (1997), who studied the SAR arcs measured by the OV1-10 photometer on 16 February, 1967. We present the results of the first calculations and studies of the SAR arc in the Southern Hemisphere observed at dusk on 4 August, 1972 (Shepherd et al., 1980).

Unusual SAR arc features observed at dusk on 4 August, 1972 in the Southern Hemisphere may be stated as follows:

1. Very high measured integral intensity at $630 \mathrm{~nm}$ (up to $10.6 \mathrm{kR}$ ) was registered.

2. SAR arcs are usually observed during recovery phase of large magnetic storms (Rees and Roble, 1975; Kozyra et al., 1997) while the studied SAR arc event was observed during the main phase of the magnetic storm.

3. SAR arcs are associated with the atomic oxygen transition $\mathrm{OI}\left({ }^{3} P_{2}-{ }^{-1} D_{2}\right)$. As a rule, the production rate of $\mathrm{O}\left({ }^{1} D\right)$ arising from the collisions of thermal electrons with $\mathrm{O}\left({ }^{3} P\right)$ is enough to explain the measured intensities (Rees and Roble, 1975; Kozyra et al., 1997). However, for some SAR arcs the resultant model intensities are much less than the measured intensities and this suggests that an additional $\mathrm{O}\left({ }^{1} D\right)$ source associated with precipitation component to SAR arc generation by soft electrons may have been present in these SAR arcs (Prasad et al., 1980; Gurgiolo et al., 1982; Slater et al., 1987; Foster et al., 1994; Kozyra et al., 1997). Of special interest to this work, the studied $630 \mathrm{~nm}$ emission can be divided into two components excited by thermal electrons and low energy precipitating electrons (Shepherd et al., 1980).

In the present study an attempt is made to model this anomalous SAR arc and illustrate the basic physics involved.

Observations of the subauroral ionosphere have confirmed that at F-region altitudes within the SAR arc the electron density is reduced and the electron temperature, $T_{e}$, is enhanced compared with the region outside the arc (Rees and Roble, 1975; Kozyra et al., 1997). It has been shown that the loss of oxygen ions due to interactions with vibrationally excited nitrogen, according to the reaction

$\mathrm{O}^{+}\left({ }^{4} S\right)+\mathrm{N}_{2}(v>0) \rightarrow \mathrm{NO}^{+}+\mathrm{N}$,

where $v$ indicates the vibrational level, is increased in SAR arc region as a result of the increased excitation of nitrogen vibrational levels by collisions with the hot thermal electrons (Newton et al., 1974; Pavlov, 1989;
Pavlov and Namgaladze, 1988). Nevertheless, Maier et al. (1975), Newton and Walker (1975), and Raitt et al. (1976) have concluded that this increase in the loss rate of $\mathrm{O}^{+}\left({ }^{4} S\right)$ as a result of the increase in the $\mathrm{N}_{2}$ vibrational temperature does not produce enough of an effect on electron density to explain the observed density decrease. However, Pavlov (1996) found that the loss rate of $\mathrm{O}^{+}\left({ }^{4} S\right)$ due to reaction (1) is enough to explain the factor of 2 electron density depression at F-region heights and the topside ionosphere density variations within the SAR arc observed on 18 December, 1971.

The measurements of the effective rate coefficient for the reaction of $\mathrm{O}^{+}\left({ }^{4} S\right)$ with $\mathrm{N}_{2}$ was given by Hierl et al. (1997) over the temperature range $300-1600 \mathrm{~K}$ for $T_{n}=T_{i}=T_{v}$, where $T_{n}$ is the neutral temperature, $T_{i}$ is the ion temperature, and $T_{v}$ is the vibrational temperature of $\mathrm{N}_{2}$. These results confirm the observations of Schmeltekopf et al. (1968) and show that the assumption of similar translation temperature dependencies for different vibrational states of $\mathrm{N}_{2}$ is reasonable. The model used in this study is the IZMIRAN time-dependent mathematical model of the Earth's ionosphere and plasmasphere (Pavlov, 1997, 1998b) using the results of Hierl et al. (1997). Such an approach gives an opportunity to study the role of $\mathrm{N}_{2}(v)$ in the formation of the electron density depression in the SAR arc region.

The important chemical processes in determining the abundance of $\mathrm{O}^{+}\left({ }^{4} S\right)$ ions are also the reaction

$\mathrm{O}^{+}\left({ }^{4} S\right)+\mathrm{O}_{2}(v) \rightarrow \mathrm{O}_{2}^{+}+\mathrm{O}$,

where $v=0,1, \ldots$ is the number of vibrational level of $\mathrm{O}_{2}$.

Hierl et al. (1997) found a big difference between the high temperature flowing afterglow and drift tube measurements (McFarland et al., 1973; Albritton et al., 1977) of the effective rate coefficient for the reaction $\mathrm{O}^{+}\left({ }^{4} S\right)$ with $\mathrm{O}_{2}$ as a result of the input of the reactions between the vibrationally excited $\mathrm{O}_{2}$ and $\mathrm{O}^{+}\left({ }^{4} S\right)$ over the temperature range $300-1800 \mathrm{~K}$ for $T_{n}=T_{i}=T_{v i b}$, where $T_{v i b}$ is the vibrational temperature of $\mathrm{O}_{2}$. Using the flowing afterglow measurements of the effective rate coefficient for the reactions of $\mathrm{O}^{+}\left({ }^{4} S\right)$ with $\mathrm{O}_{2}$ given by Hierl et al. (1997), Pavlov (1998b) evaluated the approximate contribution of each vibrational state of $\mathrm{O}_{2}(v)$ and found the partial rate coefficients for vibrational quantum number $v=1-5$ which can be used in calculations of electron densities. These new results will be used here to evaluate for the first time the role of $\mathrm{O}_{2}(v)$ in the SAR arc region.

\section{Theoretical model}

The model used is the IZMIRAN model that we have steadily developed over the years (Pavlov, 1997, 1998b). The chemistry, physics, and solution procedure have been described in details by Pavlov (1997, 1998b), and hence only a brief description of the IZMIRAN model is given. It is a one-dimensional model that uses a tilted dipole approximation to the Earth's magnetic field and takes into account the offset between the geographic and 
geomagnetic axes. In the model, coupled time dependent equations of continuity and energy balance, and diffusion equations for electrons, and $\mathrm{O}^{+}\left({ }^{4} S\right), \mathrm{H}^{+}$, and $\mathrm{He}^{+}$ ions are solved along a centred-dipole magnetic field line for the concentrations, temperatures, and field-aligned diffusion velocities of ions and electrons from a base altitude $(160 \mathrm{~km})$ in the Northern Hemisphere through the plasmasphere to the same base altitude in the Southern Hemisphere. Electron heating due to photoelectrons is provided by a solution of the Boltzmann equation for photoelectron flux. In the altitude range $120-700 \mathrm{~km}$ in the Northern and Southern Hemispheres the IZMIRAN model solves time-dependent continuity equations for $\mathrm{O}^{+}\left({ }^{2} D\right), \mathrm{O}\left({ }^{2} P\right), \mathrm{NO}^{+}, \mathrm{O}_{2}^{+}, \mathrm{N}_{2}^{+}$, and vibrationally excited molecular nitrogen, $\mathrm{N}_{2}(v)$ and oxygen, $\mathrm{O}_{2}(v)$, at the first five vibrational levels $v=1-5 . \mathrm{O}^{+}\left({ }^{4} P\right)$ and $\mathrm{O}^{+}\left({ }^{2} P^{*}\right)$ ions are also included in the IZMIRAN model as described by Pavlov (1998b). The diffusion of ions and excited species are taken into account in continuity equations for $\mathrm{NO}^{+}, \mathrm{O}_{2}^{+}, \mathrm{O}_{2}(v)$, and $\mathrm{N}_{2}(v)$. As a consequence of the large rate coefficients for chemical reactions of metastable $\mathrm{O}^{+}\left({ }^{2} D\right)$ and $\mathrm{O}^{+}\left({ }^{2} \mathrm{P}\right)$ ions with neutrals in comparison with those for $\mathrm{O}^{+}\left({ }^{4} \mathrm{~S}\right)$ ions (see Table 1 of Pavlov, 1997), the loss rate of these metastable ions is higher than the loss rate of unexcited $\mathrm{O}^{+}\left({ }^{4} S\right)$ ions by a factor of $100-1000$ while the characteristic diffusion time is the same. As a result, the role of the $\mathrm{O}^{+}\left({ }^{2} D\right)$ and $\mathrm{O}^{+}\left({ }^{2} P\right)$ diffusion is negligible in comparison with the role for chemical reactions for these metastable ions and the $\mathrm{O}^{+}\left({ }^{2} D\right)$ and $\mathrm{O}^{+}\left({ }^{2} P\right)$ diffusion is not considered in calculations of $\left[\mathrm{O}^{+}\left({ }^{2} D\right)\right]$ and $\left[\mathrm{O}^{+}\left({ }^{2} P\right)\right]$ (Torr and Torr, 1982). The chemical reactions with their rate coefficients are presented in Table 1 of Pavlov (1997) for $\mathrm{O}^{+}\left({ }^{4} S\right), \mathrm{H}^{+}, \mathrm{He}^{+}, \mathrm{O}^{+}\left({ }^{2} D\right)$, $\mathrm{O}^{+}\left({ }^{2} P\right), \mathrm{NO}^{+}, \mathrm{O}_{2}^{+}, \mathrm{N}_{2}^{+}$ions. The IZMIRAN model uses the recombination rate coefficient of $\mathrm{O}^{+}\left({ }^{4} S\right)$ ions with unexcited $\mathrm{N}_{2}(0)$ and $\mathrm{O}_{2}(0)$ and vibrationally excited $\mathrm{N}_{2}(v)$ and $\mathrm{O}_{2}(v)$ as described in detail by Pavlov (1998b). The continuity and energy equations for the vibrationally excited $\mathrm{N}_{2}$ and $\mathrm{O}_{2}$ are described by Pavlov (1997, 1998b). We use the revised electron cooling rates by vibrational and rotational excitation of $\mathrm{O}_{2}$ and $\mathrm{N}_{2}$ of Pavlov (1998a, c). The new analytical expression for atomic oxygen fine structure cooling rate of thermal electrons of Pavlov and Berrington (1999) based on the $\mathrm{O}\left({ }^{3} P\right)$ excitation cross sections of Bell et al. (1998) is included in the updated IZMIRAN model.

To calculate the density of NO the model given by Titheridge (1997) is used. We have no information on the peak altitude, hmF2, and thus can use neither the method developed by Richards (1991) nor our modification of it (Pavlov and Buonsanto, 1997) to calculate an equivalent plasma drift velocity. To overcome this problem, we use our approach described by Pavlov (1996, 1997) which allows us to avoid some serious errors in the calculations of $\mathrm{hmF} 2$ during magnetic storms (Pavlov and Buonsanto, 1997).

The updated IZMIRAN model includes the analytical yield spectrum approach developed by Green et al. (1977), Jackman and Green (1979), Singhal et al. (1979), Singhal and Green (1981), and Haider and Singhal
(1983) to calculate the fluxes of precipitating electrons in the altitude range $120-1000 \mathrm{~km}$ of Northern and Southern Hemispheres if an incident electron flux is given at the upper boundary. The validity of this approach is corroborated by the comparison of the calculated fluxes of precipitating electrons in the energy range $2 \mathrm{eV}-10 \mathrm{keV}$ and volume excitation and ionization rates from the analytical yield spectrum approach with those from Banks et al. (1974) and Mantas and Walker (1974) (see Haider and Singhal, 1983). Our implementation of this analytical method is explained in the Appendix. The electron-impact ionization cross sections of $\mathrm{N}_{2}$ and $\mathrm{O}_{2}$ are taken from Hwang et al. (1996) to calculate the additional production rates of $\mathrm{N}_{2}^{+}$ and $\mathrm{O}_{2}^{+}$ions in the SAR arc regions due to fluxes of precipitating electrons. The cross sections of Laher and Gilmore (1990) for electron-impact ionization of atomic oxygen are used to form $\mathrm{O}^{+}\left({ }^{4} S\right), \mathrm{O}^{+}\left({ }^{2} D\right), \mathrm{O}^{+}\left({ }^{2} P\right)$, and $\mathrm{O}^{+}\left({ }^{2} \mathrm{P}\right)$ ions. To calculate the additional production rate of $\mathrm{O}\left({ }^{1} D\right)$ due to precipitating electrons the excitation cross section for the $\mathrm{O}\left({ }^{3} P \rightarrow{ }^{1} D\right)$ transition, given by Doering (1992), is used.

The IZMIRAN model calculates $\left[\mathrm{O}\left({ }^{1} D\right)\right]$ from a time-dependent continuity equation in the region between 120 and $1500 \mathrm{~km}$ in altitude using production of $\mathrm{O}\left({ }^{1} D\right)$ by photodissociation of oxygen molecules, $\mathrm{O}\left({ }^{1} D\right)$ formation by collisions between $\mathrm{O}\left({ }^{3} P\right)$ and thermal electrons, precipitating electrons and photoelectrons, diffusion of $\mathrm{O}\left({ }^{1} D\right)$ through mixture of $\mathrm{N}_{2}(0), \mathrm{O}_{2}$, and $\mathrm{O}$, chemical reactions of $\mathrm{O}\left({ }^{1} D\right)$ with $\mathrm{N}_{2}, \mathrm{O}_{2}, \mathrm{O}$, and electrons, and atomic oxygen transitions $\mathrm{O}\left({ }^{1} D\right) \rightarrow$ $\mathrm{O}\left({ }^{3} P_{2}\right)+\mathrm{h} v$ at $630 \mathrm{~nm}, \quad \mathrm{O}\left({ }^{1} D\right) \rightarrow \mathrm{O}\left({ }^{3} P_{1}\right)+\mathrm{h} v$ at $636.4 \mathrm{~nm}, \mathrm{O}\left({ }^{1} D\right) \rightarrow \mathrm{O}\left({ }^{3} P_{0}\right)+\mathrm{h} v$ at $639.1 \mathrm{~nm}$ with rate and diffusion coefficients given by Pavlov (1997) (see Eqs. A24, A25, and Table 3 of Pavlov 1997). In this study we use the Einstein coefficient $A_{630}=5.61$. $10^{-3} \mathrm{~s}^{-1}$ given by Bhatia and Kastner (1995) instead of $A_{630}=5.63 \cdot 10^{-3} \mathrm{~s}^{-1}$ used by Pavlov (1997). The Einstein coefficients $A_{636.4}=1.82 \cdot 10^{-3} \mathrm{~s}^{-1}$ and $A_{639.1}=$ $8.92 \cdot 10^{-7} \mathrm{~s}^{-1}$ recommended by Bhatia and Kastner (1995) are the same as used by Pavlov (1997).

The production and loss rate of $\mathrm{O}\left({ }^{1} D\right)$ arising from the collisions of thermal electrons with $\mathrm{O}\left({ }^{3} P\right)$ includes both excitation and deexcitation of $\mathrm{O}\left({ }^{1} D\right)$ and can be calculated as (Stubbe and Varnum, 1972)

$\mathrm{P}_{\mathrm{t}}=\mathrm{N}_{\mathrm{e}} f\left(T_{e}\right)\left\{[\mathrm{O}]-\left[\mathrm{O}\left({ }^{1} D\right)\right] g_{1} g_{0}^{-1} \exp \left(E_{0} / T_{e}\right)\right\}$,

where $f\left(T_{e}\right)=\left\{8 k T_{e}\left(\pi m_{e}\right)^{-1}\right\}^{0.5} \int_{0}^{\infty} \sigma(x) x \exp (-x) d x$, $x=E\left(k T_{e}\right)^{-1}, \sigma(E)$ is the cross section for excitation of the $\mathrm{O}\left({ }^{1} D\right)$ state by electrons, $E$ is the energy of electrons, $k$ is the Boltzmann constant, $m_{e}$ denotes the mass of electron, $g_{0}$, and $g_{1}$ are statistical weights of the electron levels ${ }^{3} P$, and ${ }^{1} D$ of $\mathrm{O}, g_{1} g_{0}^{-1}=1.8$ (Radzig and Smirnov, 1980), and $E_{0}=22829 \mathrm{~K}$ (or $1.97 \mathrm{eV}$ ) is the energy of the $\mathrm{O}\left({ }^{1} D\right)$ electron level given by Radzig and Smirnov (1980).

The analytical formula for $f\left(T_{e}\right)$ which was used in the IZMIRAN model was based on $\sigma(E)=$ $\sigma_{0} E_{0}\left(1-E_{0} / E\right)^{2} / E$ where the value of $\sigma_{0}$ was determined by fitting this $\sigma(E)$ to the measured (Doering and Gulcicek, 1989) and theoretical (Thomas and Nesbet, 
1975) cross sections (Pavlov, 1996; 1997). The value of $\sigma(E)$ has been measured by Doering (1992) for incident electron impact energies of 4.0 to $30 \mathrm{eV}$. To find a more accurate analytical expression for $f\left(T_{e}\right)$ we used the linear interpolation of $\sigma(E)$ measured by Doering (1992) between fixed incident energies from the threshold (where $\sigma(E)=0$ ) to $30 \mathrm{eV}$. This assumption leads to the simple approach in calculations of $f\left(T_{e}\right)$ as

$f\left(T_{e}\right)=4.71 \cdot 10^{-12} T_{e}^{0.7}\left(1+6.25 \cdot 10^{-10} T_{e}^{2}\right) \exp \left(-E_{0} / T_{e}\right)$,

where the unit of $f\left(T_{e}\right)$ is $\mathrm{cm}^{3} \mathrm{~s}^{-1}$.

We found that the value of maximum error for this analytical expression for $f\left(T_{e}\right)$ is less than $2 \%$ within the electron temperature range $1300-8000 \mathrm{~K}$, and this accuracy is enough for our studies. It should be noted that the difference between the new and old IZMIRAN model values of $f\left(T_{e}\right)$ is less than $10 \%$ within the electron temperature range $2500-8000 \mathrm{~K}$.

The revised cooling rate in collision of $\mathrm{O}\left({ }^{3} P\right)$ with thermal electrons with the $\mathrm{O}\left({ }^{1} D\right)$ formation is given as

$\mathrm{L}\left(\mathrm{O}\left({ }^{1} D\right)\right)=E_{0} \mathrm{P}_{\mathrm{t}}$.

The IZMIRAN model electron heating due to photoelectrons is provided by a solution of the Boltzmann equation for photoelectron flux (Pavlov, 1997). As the incident electrons penetrate the Earth's atmosphere they lose energy not only by ionizing and exciting the neutral constituents but also by heating thermal electrons, $Q_{p r}$. The updated IZMIRAN model uses the value of $Q_{p r}$ given by Eq. (16) of Lummerzheim and Lilensten (1994).

The rate coefficient for quenching of $\mathrm{O}^{+}\left({ }^{2} D\right)$ by atomic oxygen has not been measured in the laboratory and have assumed as $10^{-10} \mathrm{~cm}^{3} \mathrm{~s}^{-1}$ (see discussion given by Pavlov 1997, 1998b). The MSIS-86 model (Hedin, 1987) with $3 \mathrm{~h} A p$ indices is included in the IZMIRAN model to simulate magnetic storm effects on the neutral atmosphere. The IZMIRAN model uses the solar EUV fluxes from EUVAC model (Richards et al., 1994) in this work. At night our model includes ionization by scattered solar fluxes. The numerical technique for the numerical solution of the continuity, momentum and energy equations given by Marov and Kolesnichenko (1987) (Supplement II) is used in the IZMIRAN model. This numerical technique that we use is similar to that described by Hastings and Roble (1977). The solving patterns of the IZMIRAN model calculations were given by Marov and Kolesnichenko (1987), Pavlov (1989a, b, 1996, 1997, 1998b) and Pavlov and Buonsanto (1997).

\section{Results}

The 4-6 August, 1972 geomagnetic storm period occurred during medium solar activity $(\mathrm{F} 10.7=146-$ 147). The detailed description of the planetary magnetic index $K_{p}$ and $D s t$ for this period is given by Hoffman et al. (1975). A double sudden storm commencement occurred near the beginning of August 4 at 0119 UT and
0220 UT and was followed by a moderate main phase. During the main phase of the geomagnetic storm, the Dst index is decreased when the ring current builds up. The planetary index $K_{p}$ reached $8_{+}$and $9_{0}$ on 4 August at $0300 \mathrm{UT}$ and $2100 \mathrm{UT}$. The recovery phase of the first geomagnetic storm began near 0700 UT on 4 August with $D s t=-118 \gamma$. The next sudden commencement occurred at 2054 UT on 4 August.

Observations of the ion composition and electron temperature at $1400 \mathrm{~km}$ altitude and density height profiles from the altitude of the ISIS II spacecraft down to the $\mathrm{F}$ region, the intensity and the volume emission rate profile of the $630 \mathrm{~nm}$ oxygen emission in the SAR arc region are presented by Shepherd et al. (1975). The comparison between the ISIS II data and the IZMIRAN numerical results discussed here corresponds to the conditions of the SAR arc region in the Southern Hemisphere on 4 August, 1972 at 05:57:51 UT (the invariant latitude $60.7^{\circ}$ and geographic longitude $170^{\circ}$, $\mathrm{L}$ shell value of the geomagnetic field is 4.175). The Explorer $45\left(\mathrm{~S}^{3}-\mathrm{A}\right)$ spacecraft observations at $0600 \mathrm{UT}$ on 4 August placed the plasmapause at $\mathrm{L}=4.2$ (Hoffman et al., 1975) and this shows that the measured ISIS II SAR arc enhancements in $T_{e}$, and a part of the related SAR arc emission is closely associated with processes at the plasmapause.

To explain electron temperature enhancements and the associated SAR arcs the IZMIRAN model includes the additional heating rate, $q$, of the electron gas in plasmasphere due to Coulomb collisions between ring current ions and plasmaspheric electrons and ions and wave-particle interactions (Pavlov, 1997). There is no information available on the ring-current population and wave-particle interactions for this storm, and we are therefore forced to assume an additional heating rate, $q$, should be added to the normal photoelectron heating in the electron energy equation in the plasmasphere region $-s_{0}<s<s_{0}$ above $5000 \mathrm{~km}$ along the magnetic field line in agreement with previous works of Pavlov (1996, 1997) concerning the rate of energy transfer from the energetic ring current ions to plasmaspheric electrons. We found that good agreement between the measured and modelled electron temperature is obtained if the value of $q=1.05 \mathrm{eV} \mathrm{cm}^{-3} \mathrm{~s}^{-1}$ is selected during all storm time periods ( $q=0$ for undistributed conditions).

\subsection{Electron flux spectra}

The ISIS II soft particle spectrometer measured an energy spectrum of electrons and four of these spectra at pitch angles of $55^{\circ}, 31^{\circ}, 14^{\circ}$, and $73^{\circ}$ on 4 August, 1972 at 05:57:35 UT, 05:57:51 UT, 05:58:07 UT, and 05:58:23 UT are presented by Shepherd et al. (1975). The onset and the time duration of this soft electron flux event were not measured. The rarity of soft electron flux observations over SAR arcs does not allow us to evaluate the typical time characteristics of these events from other observations. Prasad et al. (1980) found that the soft electron flux data were obtained about $40 \mathrm{~min}$ before the occurrence of the SAR arc on orbit 8715 of 
OGO 6 satellite and observed during orbit 8714 of OGO 6 satellite about 2 h 20 min before the birth of the SAR arc. Typical auroral events produced by electron precipitation are considered with a lifetime of electron precipitation events lasting from a few minutes to about an hour (Roble and Rees, 1977). As a result, we assume that the electron precipitation studied is realized from 05:30:00 UT to 6:30:00 UT, and the spectrum of incident electrons is the same during this time period.

We have no measurements of full pitch angular distributions of incident electrons for the studied SAR arc. As a result, we use the isotropy assumption for the incident electron flux. Our model calculates the fluxes of precipitating electrons integrated over pitch angles in the altitude range $120-1000 \mathrm{~km}$ covering the energy range from $0.5 \mathrm{eV}$ to $52 \mathrm{keV}$ if an incident electron flux, $F_{\infty}(E)$, is given at the upper boundary (see Appendix). The measured differential electron energy spectra, $U(E)$, shown in Fig. 4 of Shepherd et al. (1975) with energies from $6 \mathrm{eV}$ to $8 \mathrm{eV}$ at the mentioned four moments of time changed rapidly in a spatial sense. For energies below $6 \mathrm{eV}$ and above $8 \mathrm{keV}$, where there are no measurements of $U(E)$, we assumed that $\log U(E)=A+B \log E$ (linear interpolation), and found the values of $A$ and $B$ from the measured spectra of Shepherd et al. (1975) at $6 \mathrm{eV}$ and $8.5 \mathrm{eV}$ (for $E<6 \mathrm{eV}$ ) and $5.2 \mathrm{keV}$ and $8 \mathrm{keV}$ (for $E>8 \mathrm{keV}$ ). We found that the best agreement between the modelled and measured volume emission rates at $630 \mathrm{~nm}$ is obtained if the approach of $F_{\infty}(E)=0.2 U(E)$ is used during the electron precipitation time period, where $U(E)$ is the value of the measured spectra at the pitch angle of $31^{\circ}$ at 05:57:51 UT, $E$ is an energy of electrons.

The dashed line in Fig. 1 shows the incident electron flux. The calculated flux of precipitating electrons at $300 \mathrm{~km}$ at 05:57:51 UT on August 4 is shown by solid line in Fig. 1. The incident flux can be seen centred at $21 \mathrm{eV}$ in Fig. 1. At altitudes $1000 \mathrm{~km}$ and $300 \mathrm{~km}$, there is very little degradation of this initial flux in the energy range between $50 \mathrm{eV}$ and $250 \mathrm{eV}$ but the degradation is very noticeable above $800-1000 \mathrm{eV}$. At $300 \mathrm{~km}$, the electron flux is orders of magnitude larger than the incident electron flux at low energies $2-14 \mathrm{eV}$.

\subsection{Modelling the $S A R$ arc emission at $630 \mathrm{~nm}$}

Important characteristics of airglow are the volume emission rate and the integral intensity at $630 \mathrm{~nm}$ that are calculated by the model as

$V_{630}=A_{630}\left[\mathrm{O}\left({ }^{1} D\right)\right], I_{630}(z)=\int_{z}^{\infty} V_{630}(\mathrm{~h}) \mathrm{dh}$,

where $z$ is an altitude.

Figure 2 shows the measured (crosses) volume emission rates at $630 \mathrm{~nm}$ as extracted by Shepherd et al. (1980) from the tomographic inversion at 05:57:40-05:57:51 UT on August 4 in the SAR-arc region in comparison with the calculated (lines) $630 \mathrm{~nm}$ volume emission rates. The solid line shows the

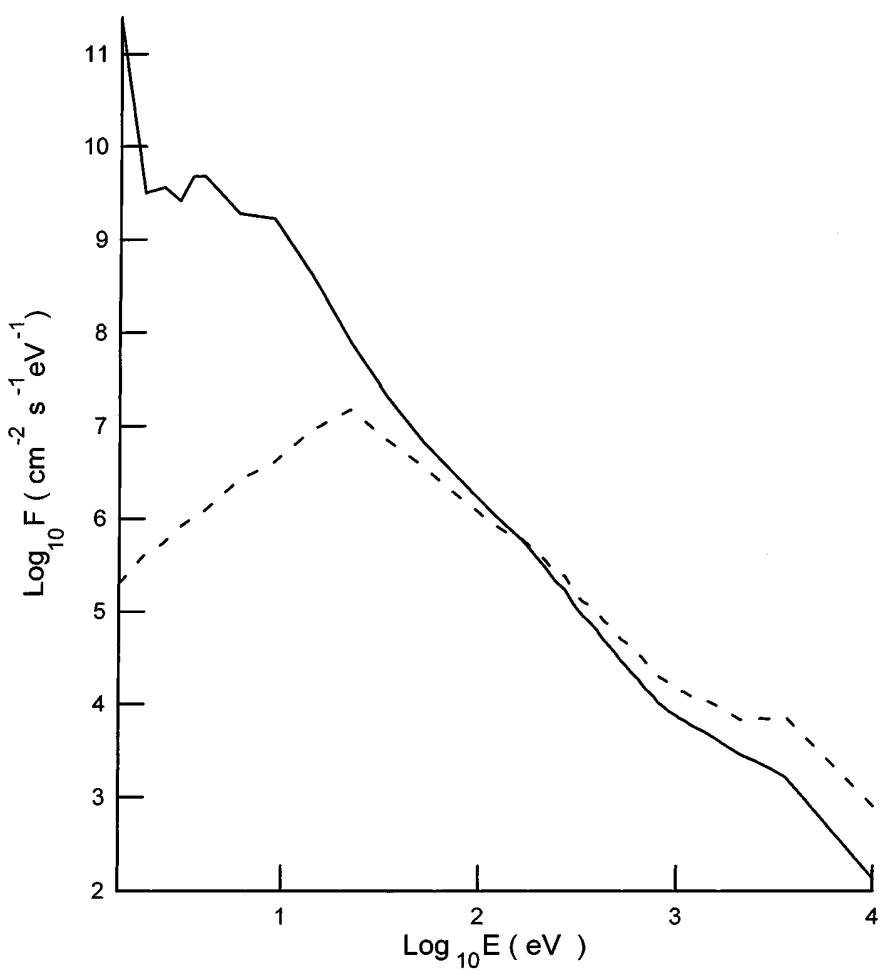

Fig. 1. The calculated flux of precipitating electrons at $300 \mathrm{~km}$ at 05:51:51 UT on August 4 in the SAR-arc region (solid line) for the incident electron flux (dashed line)

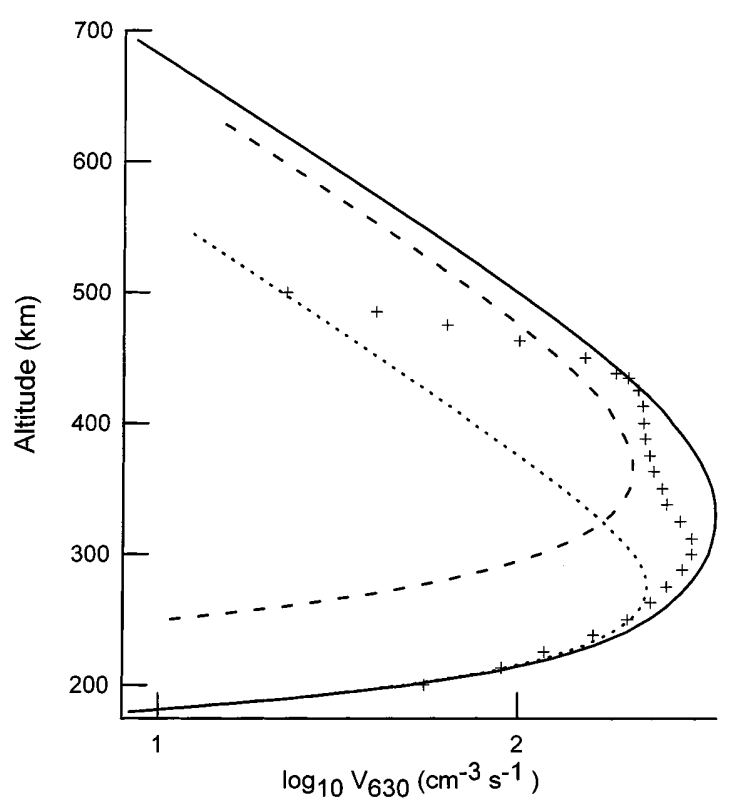

Fig. 2. Observed (crosses) and calculated (lines) $630 \mathrm{~nm}$ volume emission rates at 05:51:40-05:51:51 UT on August 4 in the SAR-arc region. The modelled volume emission rates were obtained when the IZMIRAN model includes the additional heating rate of the electron gas in the plasmasphere $q=1.05 \mathrm{eV} \mathrm{cm}^{-3} \mathrm{~s}^{-1}$ and the fluxes of precipitating electrons of Fig. 1 (solid line) for the geomagnetic storm period. The dotted line shows the volume emission rate from the IZMIRAN model with the fluxes of precipitating electrons and without the additional heating rate of the electron gas in the plasmasphere. The dashed line represents the IZMIRAN model results with $q=1.05 \mathrm{eV} \mathrm{cm}^{-3} \mathrm{~s}^{-1}$ in the plasmasphere and without $\mathrm{O}\left({ }^{1} D\right)$ formation by collisions between $\mathrm{O}\left({ }^{3} P\right)$ and precipitating electrons 
IZMIRAN model results when the calculated fluxes of precipitating electrons of Fig. 1 and the additional heating rate of the electron gas in the plasmasphere of $1.05 \mathrm{eV} \mathrm{cm}^{-3} \mathrm{~s}^{-1}$ are used to agree the modelled and measured electron temperature as discussed later and to explain the excitation of the SAR arc observed. Our model calculates the $630 \mathrm{~nm}$ integral intensity above $350 \mathrm{~km}$ of $4.1 \mathrm{kR}$ and the total $630 \mathrm{~nm}$ integral intensity, $I_{630}(0)=8.1 \mathrm{kR}$, which are slightly lower compared to $I_{630}(350)=4.7 \mathrm{kR}$ and $I_{630}(0)=10.6 \mathrm{kR}$ that were observed by Shepherd et al. (1980). This difference between the measured and modelled $I_{630}(z)$ and the big disagreement between the measured and calculated $V_{630}(z)$ at altitudes above $460-470 \mathrm{~km}$ is probably due to errors of the tomographic inversion method and errors of the IZMIRAN model calculations (effects of uncertainties in the solar fluxes and neutral temperature and densities on the calculated electron density and temperature, and effects of uncertainties in the fluxes of precipitating electrons on the $\mathrm{O}\left({ }^{1} D\right)$ production rate). The heat flow requirement for the SAR arc was earlier estimated to be $0.16 \mathrm{erg} \mathrm{cm}^{-2} \mathrm{~s}^{-1}$ (Shepherd et al., 1980) compared with the value $0.11 \mathrm{erg} \mathrm{cm}^{-2} \mathrm{~s}^{-1}$ of the flux of thermal electrons at $1400 \mathrm{~km}$ from IZMIRAN model.

The dotted line in Fig. 2 shows the volume emission rate from the IZMIRAN model with the fluxes of precipitating electrons and without the additional heating rate of the electron gas in the plasmasphere. The calculated integral intensity above $350 \mathrm{~km}$ and total integral intensity are about $1.1 \mathrm{kR}$ and $3.8 \mathrm{kR}$, and these values are much smaller than those measured by Shepherd et al. (1980). This model gives the peak volume emission rate at $280 \mathrm{~km}$ in agreement with the measured one. However, the observed higher altitude component of $V_{630}(z)$, with its peak near $400 \mathrm{~km}$ cannot be explained by effects of precipitating electrons, and our results confirm the conclusion of Shepherd et al. (1980) that the upper component was excited through the $\mathrm{O}\left({ }^{1} D\right)$ formation by collisions between $\mathrm{O}\left({ }^{3} P\right)$ and thermal electrons.

The dashed line (Fig. 2) represents the IZMIRAN model results with $q=1.05 \mathrm{eV} \mathrm{cm}^{-3} \mathrm{~s}^{-1}$ in the plasmasphere and without precipitation component to SAR arc generation by soft electrons. This model predicts $I_{630}(350)=2.9 \mathrm{kR}$ and $I_{630}(0)=4.0 \mathrm{kR}$ with the peak volume emission rate located at $360 \mathrm{~km}$, which is lower than the measured higher altitude component peak of $V_{630}(z)$. Like the model result shown by the dotted line, the $630 \mathrm{~nm}$ integral intensity above $350 \mathrm{~km}$ and total $630 \mathrm{~nm}$ integral intensity given by this model are significantly smaller than those observed.

We conclude that the comparison between the measured and modelled $V_{630}(z), I_{630}(350)$, and $I_{630}(0)$ indicates that our model reproduces major features of the data, and the $630 \mathrm{~nm}$ emission observed can be explained taking into account both the soft energy electron excited component with the incident electron flux given at $1000 \mathrm{~km}$ altitude as $0.2 U(E)$ and the thermally excited component with $q=1.05 \mathrm{eV} \mathrm{cm}^{-3} \mathrm{~s}^{-1}$ in the plasmasphere.

\subsection{Modelling the $S A R$ arc emission at $557.7 \mathrm{~nm}$}

The $557.7 \mathrm{~nm}$ green line is the result of the transition

$\mathrm{O}\left({ }^{1} S\right) \rightarrow \mathrm{O}\left({ }^{1} D\right)+\mathrm{h} v$,

with the Einstein coefficient $\mathrm{A}_{557.7}=1.22 \mathrm{~s}^{-1}$ given by Bhatia and Kastner (1995).

The volume emission rate and integral intensity at $557.7 \mathrm{~nm}$ are calculated by the model as

$V_{557.7}=\mathrm{A}_{557.7}\left[\mathrm{O}\left({ }^{1} S\right)\right], I_{557.7}(z)=\int_{z}^{\infty} V_{557.7}(\mathrm{~h}) \mathrm{dh}$

Production processes for the $\mathrm{O}\left({ }^{1} S\right)$ state considered in the present analysis include the direct excitation processes by precipitating $(e)$ and thermal $\left(e_{t}\right)$ electrons as

$e+\mathrm{O}\left({ }^{3} P\right) \rightarrow \mathrm{O}\left({ }^{1} S\right)+e$,

$e+\mathrm{O}_{2} \rightarrow \mathrm{O}\left({ }^{1} S\right)+\mathrm{O}+e$,

$e_{t}+\mathrm{O}\left({ }^{3} P\right) \rightarrow \mathrm{O}\left({ }^{1} S\right)+e_{t}$,

To calculate the production rate of $\mathrm{O}\left({ }^{1} S\right)$ from the excitation of $\mathrm{O}\left({ }^{3} P\right)$ by precipitating electrons we use the $\mathrm{O}\left({ }^{3} P\right)$ excitation cross section given by Doering and Gulcicek (1989). The production rate of $\mathrm{O}\left({ }^{1} S\right)$ following the dissociation of $\mathrm{O}_{2}$ by precipitating electron impact is calculated by the use of the cross section for the production of $\mathrm{O}\left({ }^{1} S\right)$ given by LeClair and McConkey (1993). The production rate of $\mathrm{O}\left({ }^{1} S\right)$ due to process (11) can be calculated as by (Stubbe and Varnum, 1972)

$\mathrm{P}_{\mathrm{et}}\left(\mathrm{O}\left({ }^{1} S\right)\right)=N_{e} f_{1} T_{e}[\mathrm{O}]$,

where $f_{1}\left(T_{e}\right)=\left\{8 k T_{e}\left(\pi m_{e}\right)^{-1}\right\}^{0.5} \int_{0}^{\infty} \sigma_{1}(x) x \exp (-x) d x$, $x=E\left(k T_{e}\right)^{-1}$, and $\sigma_{1}(E)$ is the cross section for excitation of the $\mathrm{O}\left({ }^{1} S\right)$ state by electrons.

The linear interpolation of $\sigma_{1}(E)$ measured by Doering and Gulcicek (1989) leads to the simple approach in calculations of $f_{1}\left(T_{e}\right)$ as

$f_{1}\left(T_{e}\right)=1.29 \cdot 10^{-11} T_{e}^{0.6} \exp \left(-E_{0 \mathrm{~S}} / T_{e}\right)$,

where $E_{0 \mathrm{~S}}=48618 \mathrm{~K}$ (or $4.1896 \mathrm{eV}$ ) is the energy of the $\mathrm{O}\left({ }^{1} S\right)$ electron level given by Radzig and Smirnov (1980), and the unit of $f_{1}\left(T_{e}\right)$ is $\mathrm{cm}^{3} \mathrm{~s}^{-1}$.

We found that the value of maximum error for this analytical expression for $f_{1}\left(T_{e}\right)$ is less than $2 \%$ within the electron temperature range 1400-6000 K, and this accuracy is enough in our studies.

The chemical reactions

$\mathrm{O}_{2}^{+}+e_{t} \rightarrow \mathrm{O}\left({ }^{3} P\right)+\mathrm{O}\left({ }^{1} S\right)$,

$\mathrm{N}_{2}\left(A^{3} \Sigma_{u}^{+}, j\right)+\mathrm{O}\left({ }^{3} P\right) \rightarrow \mathrm{N}_{2}+\mathrm{O}\left({ }^{1} S\right)$

are also included in our study as production processes for the $\mathrm{O}\left({ }^{1} S\right)$ state. The total rate coefficient of dissociative recombination of $\mathrm{O}_{2}^{+}$ions used in the IZMIRAN model is given by Pavlov (1997). The quantum yield of $\mathrm{O}\left({ }^{1} S\right)$ from dissociative recombination of $\mathrm{O}_{2}^{+}$in the vibrational levels 1 and 2 may vary between 
0.09 and 0.23 (Yee and Killeen, 1986), and we use a quantum yield of 0.15 .

The interaction between $\mathrm{N}_{2}\left(A^{3} \Sigma_{u}^{+}, j\right)$ at vibrational levels $j=0-7$ with $\mathrm{O}\left({ }^{3} P\right)$ give rise to many reaction channels with the total rate coefficients measured by Thomas and Kaufman (1985) for $j=0,1$ and De Benedicctis and Dilecce (1997) for $j=2-7$. The formation products are enumerated: $\mathrm{N}_{2}+\mathrm{O}\left({ }^{1} S\right)$, $\mathrm{N}_{2}+\mathrm{O}\left({ }^{3} P\right), \quad \mathrm{N}_{2}+\mathrm{O}\left({ }^{1} D\right), \quad \mathrm{NO}+\mathrm{N}\left({ }^{4} S\right), \quad \mathrm{NO}+\mathrm{N}\left({ }^{2} D\right)$. Piper (1981) has measured a value of 0.75 for the quantum yield of $\mathrm{O}\left({ }^{1} S\right)$ from $\mathrm{N}_{2}\left(A^{3} \Sigma_{u}^{+}, j=0\right)+\mathrm{O}\left({ }^{3} P\right)$. However, aurora and airglow emission studies (Gattinger et al., 1985, Singh et al., 1996) have suggested that this value is not appropriate for the other vibrational levels, and we use a value of 0.36 recommended by Singh et al. (1996).

Loss processes considered for the $\mathrm{O}\left({ }^{1} S\right)$ state include radiative decay given by $\mathrm{Eq}$. (7) and

$\mathrm{O}\left({ }^{1} S\right) \rightarrow \mathrm{O}\left({ }^{3} P_{1}\right)+\mathrm{h} v$

$\mathrm{O}\left({ }^{1} S\right) \rightarrow \mathrm{O}\left({ }^{3} P_{2}\right)+\mathrm{h} v$

with the Einstein coefficients $7.6 \cdot 10^{-2} \mathrm{~s}^{-1}$ and $2.73 \cdot 10^{-4} \mathrm{~s}^{-1}$ given by Bhatia and Kastner (1995), and the collisional deactivation processes

$\mathrm{O}\left({ }^{1} S\right)+\mathrm{O}\left({ }^{3} P\right) \rightarrow \mathrm{O}+\mathrm{O}$

$\mathrm{O}\left({ }^{1} S\right)+\mathrm{O}_{2} \rightarrow \mathrm{O}+\mathrm{O}_{2}$.

we use the rate coefficient of $5 \cdot 10^{-11} \exp \left(-305 T_{n}^{-1}\right)$ $\mathrm{cm}^{3} \mathrm{~s}^{-1}$ for reaction (18) (Slanger and Black, 1981) and the rate coefficient of $4 \cdot 10^{-12} \exp \left(-865 T_{n}^{-1}\right) \mathrm{cm}^{3} \mathrm{~s}^{-1}$ for the reaction (19) (Slannger et al., 1972).

The values of $V_{557.7}(z)$ and $I_{557.7}(z)$ are functions of $\left[\mathrm{N}_{2}\left(A^{3} \Sigma_{u}^{+}, j\right)\right]$ which depends on number densities of $\mathrm{N}_{2}\left(B^{3} \Pi_{g}^{+}, i\right)$ and $\mathrm{N}_{2}\left(C^{3} \Pi_{u}, n\right)$ at vibrational levels " $i$ " and " $n$ " (Torr and Torr, 1982). To calculate the production rates, $Q(A, j), Q(B, i)$, and $Q(C, n)$, of $\mathrm{N}_{2}\left(A^{3} \Sigma_{u}^{+}, j\right), \mathrm{N}_{2}\left(B^{3} \Pi_{g}^{+}, i\right)$, and $\mathrm{N}_{2}\left(C^{3} \Pi_{u}, n\right)$ from the excitation of the $\mathrm{N}_{2}$ ground state by precipitating electrons we use the $\mathrm{N}_{2}\left(A^{3} \Sigma_{u}^{+}\right), \mathrm{N}_{2}\left(B^{3} \Pi_{g}^{+}\right)$, and $\mathrm{N}_{2}\left(C^{3} \Pi_{u}\right)$ excitation cross sections given by Majeed and Strickland (1997) and the Franc-Condon factors for these transitions presented by Gilmore et al. (1992) and Piper (1993).

The $\mathrm{N}_{2}\left(C^{3} \Pi_{u}, n\right)$ loss processes include the radiative decay through the $\mathrm{N}_{2}$ second positive bands as $\mathrm{N}_{2}\left(C^{3} \Pi_{u}, n\right) \rightarrow \mathrm{N}_{2}\left(B^{3} \Pi_{g}^{+}, i\right)+\mathrm{h} v$. A complete set of the Einstein coefficients, $A_{\mathrm{ni}}(C, B)$, (Gilmore et al., 1992) for these processes allows one to calculate

$$
\left[\mathrm{N}_{2}\left(C^{3} \Pi_{u}, n\right)\right]=Q(C, n)\left\{\sum_{i} A_{\mathrm{ni}}(C, B)\right\}^{-1} .
$$

Similarly, the $\mathrm{N}_{2}$ first positive bands arise from the transitions $\mathrm{N}_{2}\left(B^{3} \Pi_{g}^{+}, i\right) \rightarrow \mathrm{N}_{2}\left(A^{3} \Sigma_{u}^{+}, j\right)+\mathrm{h} v$, with the Einstein coefficients, $A_{i j}(B, A)$, given by Gilmore et al. (1992). This radiative decay determines the sinks of the $\mathrm{N}_{2}\left(B^{3} \Pi_{q}^{+}, i\right)$ state, so that

$$
\begin{aligned}
{\left[\mathrm{N}_{2}\left(B^{3} \Pi_{g}^{+}, i\right)\right]=} & \left\{Q(B, i)+\sum_{n} A_{\mathrm{ni}}(C, B)\left[\mathrm{N}_{2}\left(C^{3} \Pi_{u}, n\right)\right]\right\} \\
& \times\left\{\sum_{j} A_{i j}(B, A)\right\}^{-1}
\end{aligned}
$$

The model calculations include the collisional deactivation's processes for the $\mathrm{N}_{2}\left(A^{3} \Sigma_{u}^{+}, j=0-7\right)$ state by $\mathrm{O}\left({ }^{3} P\right), \mathrm{O}_{2}$, and $\mathrm{NO}$ with the measured rate coefficients, $K_{j}(\mathrm{O}), K_{j}\left(\mathrm{O}_{2}\right)$, and $K_{j}(\mathrm{NO})$, given in Table II of De Benedicctis and Dilecce (1997). The reaction rate coefficient for quenching by $\mathrm{N}_{2}$ is less than $10^{-18} \mathrm{~cm}^{3} \mathrm{~s}^{-1}$ (Torr and Torr, 1982), and this process can be neglected in comparison with other quenchers of $\mathrm{N}_{2}\left(A^{3} \Sigma_{u}^{+}, j\right)$. The $\mathrm{N}_{2}\left(A^{3} \Sigma_{u}^{+}, j\right)$ loss processes considered include also radiative decay given by $\mathrm{N}_{2}\left(A^{3} \Sigma_{u}^{+}, j\right) \rightarrow \mathrm{N}_{2}\left(X^{1} \Sigma_{g}^{+}, v\right)+\mathrm{h} v$ which determines the Vegard-Kaplan emission with the Einstein coefficients, $A_{j v}(A, X)$, given by Piper (1993). As a result, one obtains:

$$
\begin{aligned}
{\left[\mathrm{N}_{2}\left(A^{3} \Sigma_{u}^{+}, j\right)\right]=} & \left\{Q(A, j)+\sum_{i} A_{i j}(B, A)\left[\mathrm{N}_{2}\left(B^{3} \Pi_{g}^{+}, i\right)\right]\right\} \\
& \times\left\{\sum_{v} A_{j v}(A, X)+K_{j}(\mathrm{O})\right. \\
& \left.+K_{j}\left(\mathrm{O}_{2}\right)+K_{j}(\mathrm{NO})\right\}^{-1} .
\end{aligned}
$$

As far as the authors know, the values of $K_{j}(\mathrm{O}), K_{j}\left(\mathrm{O}_{2}\right)$, and $K_{j}(\mathrm{NO})$ are not measured and not calculated at vibrational levels $j>7$, and our model calculates $\left[\mathrm{N}_{2}\left(A^{3} \Sigma_{u}^{+}, j=0, \ldots 7\right)\right]$.

Shepherd et al. (1980) did not publish the measured $V_{557.7}(z), I_{557.7}(z)$ in the studied SAR arc region, and we can only study the role of the sources of $\mathrm{O}\left({ }^{1} S\right)$ described in production of the $557.7 \mathrm{~nm}$ green line in the altitude range from $120 \mathrm{~km}$ to $1000 \mathrm{~km}$. Figure 3 shows the calculated altitude profile of the total volume emission rate at $557.7 \mathrm{~nm}$ (solid line) in the SAR arc region at 05:51:51 UT on 4 August, 1972, in comparison with the volume emission rate altitude profiles at $557.7 \mathrm{~nm}$ due to collisions of $\mathrm{O}\left({ }^{3} \mathrm{P}\right)$ with precipitating (dashed line 1) and thermal (dashed line 2) electrons, dissociative recombination of $\mathrm{O}_{2}^{+}$ions (dashed line 3), excitation of $\mathrm{O}\left({ }^{1} S\right)$ in the reaction between $\mathrm{N}_{2}\left(A^{3} \Sigma_{u}^{+}\right)$and $\mathrm{O}\left({ }^{3} P\right)$ (dashed line 4).

It is evident from the profiles shown in Fig. 3 that the excitation process producing $\mathrm{O}\left({ }^{1} S\right)$ directly, electron impact on ambient $\mathrm{O}\left({ }^{3} P\right)$, and the reaction of $\mathrm{N}_{2}\left(A^{3} \Sigma_{u}^{+}\right)$ and $\mathrm{O}\left({ }^{3} P\right)$ are the dominant production mechanisms for $\mathrm{O}\left({ }^{1} S\right)$ below about $480 \mathrm{~km}$. It is also apparent that the interaction between $\mathrm{N}_{2}\left(A^{3} \Sigma_{u}^{+}, j\right)$ with $\mathrm{O}\left({ }^{3} P\right)$ is the dominant production source of $\mathrm{O}\left({ }^{1} S\right)$ at altitudes less than $190 \mathrm{~km}$. We found also that the volume emission rate of $\mathrm{O}\left({ }^{1} S\right)$ due to the production rate of $\mathrm{O}\left({ }^{1} S\right)$ following the dissociation of $\mathrm{O}_{2}$ by precipitating electrons is less than $0.2 \mathrm{~cm}^{-3} \mathrm{~s}^{-1}$, and this source of $\mathrm{O}\left({ }^{1} S\right)$ production rate due to the three body recombination source $\mathrm{O}+\mathrm{O}+\mathrm{M}$ can be considered as the source of $\mathrm{O}\left({ }^{1} S\right)$ below 100-110 km (see, e.g., Singh et al., 1997). Our model calculates $\left[\mathrm{O}\left({ }^{1} S\right)\right]$ above $120 \mathrm{~km}$, and this source of $\mathrm{O}\left({ }^{1} S\right)$ is not included in the present analysis. 


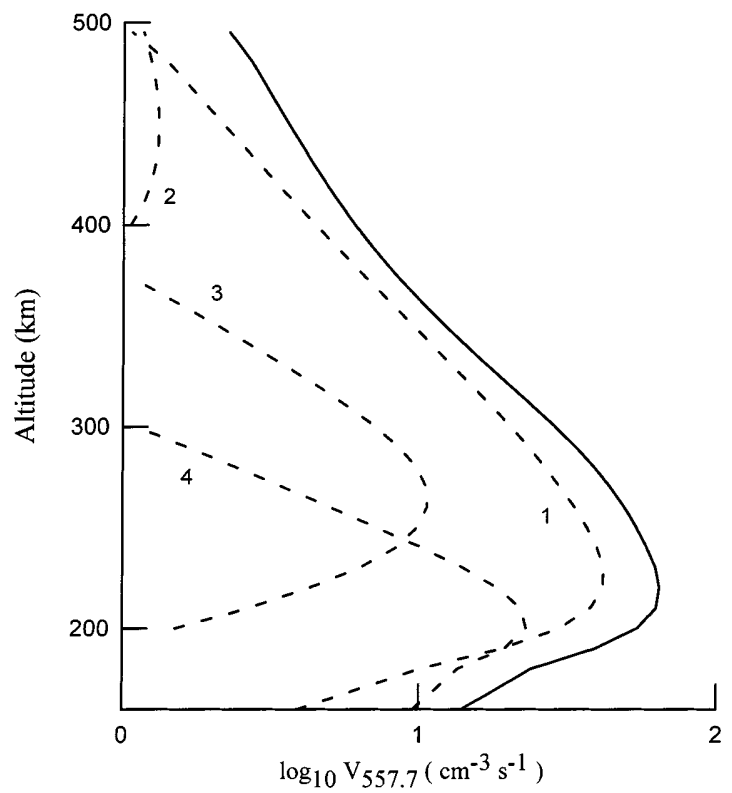

Fig. 3. The IZMIRAN model altitude profile of the total $557.7 \mathrm{~nm}$ volume emission rate (solid line) in comparison with the volume emission rate altitude profiles at $557.7 \mathrm{~nm}$ due to the sources of $\mathrm{O}\left({ }^{1} S\right)$ (dashed lines 1-5) in the SAR arc region at 05:51:51 UT on 4 August, 1972. Lines 1 and 2 represent the volume emission rates due to collisions of $\mathrm{O}\left({ }^{3} P\right)$ with precipitating and thermal electrons, respectively. Line 3 shows the volume emission rate determined by dissociative recombination of $\mathrm{O}_{2}^{+}$ions. The volume emission rate produced by excitation of $\mathrm{O}\left({ }^{1} S\right)$ in the reaction between $\mathrm{N}_{2}\left(A^{3} \Sigma_{u}^{+}\right)$ and $\mathrm{O}\left({ }^{3} P\right)$ is shown by curve 4

The model predicts $I_{557.7}(350)=101 R, I_{557.7}(200)=$ $705 R$, and $I_{557.7}(160)=822 R$ with the $557.7 \mathrm{~nm}$ peak volume emission rate located at $220 \mathrm{~km}$, which is lower than the measured altitude component peaks of $V_{630}(z)$. One of the main properties of SAR arcs is that their dominant spectral line is the $630 \mathrm{~nm}$ line of atomic oxygen (Rees and Roble, 1975). Our results show that $I_{557.7}(z)<<I_{630}(z)$, and the most likely identification of this feature is a SAR arc.

\subsection{Effects of vibrational excited oxygen and nitrogen on electron density}

The loss rate of $\mathrm{O}^{+}\left({ }^{4} S\right)$ ions is given as

$\mathrm{L}=\sum_{v=0}^{\infty}\left[\mathrm{N}_{2}(v)\right] K_{1 v}+\sum_{v=0}^{\infty}\left[\mathrm{O}_{2}(v)\right] K_{2 v}$,

where $K_{1 v}$ is the recombination rate coefficient of $\mathrm{O}^{+}\left({ }^{4} S\right)$ ions with $\mathrm{N}_{2}(v)$ (Schmeltekopf et al., 1968; Hierl et al., 1997; Pavlov, 1998b), $K_{2 v}$ is the recombination rate coefficient of $\mathrm{O}^{+}\left({ }^{4} S\right)$ ions with $\mathrm{O}_{2}(v)$ (Hierl et al., 1997; Pavlov, 1998b), and $v$ is the number of the $\mathrm{N}_{2}$ or $\mathrm{O}_{2}$ ground state vibrational level.

The IZMIRAN model calculates non-Boltzmann distributions of vibrationally excited molecular nitrogen and oxygen and includes the option to use the model of the Boltzmann distributions of $\mathrm{N}_{2}(v)$ and $\mathrm{O}_{2}(v)$ as (Pavlov, 1997, 1998b)

$$
\begin{aligned}
& {\left[\mathrm{N}_{2}(v)\right]_{B}=\left[\mathrm{N}_{2}(0)\right]_{B} \exp \left(-v 3353 T_{v}^{-1}\right),} \\
& {\left[\mathrm{O}_{2}(v)\right]_{B}=\left[\mathrm{O}_{2}(0)\right]_{B} \exp \left(-v 2239 T_{v i b}^{-1}\right),}
\end{aligned}
$$

where $T_{v}$ is the vibrational temperature of $\mathrm{N}_{2}(v)$, and $T_{v i b}$ is the vibrational temperature of $\mathrm{O}_{2}(v)$.

The results of calculating $\left[\mathrm{O}_{2}(v)\right] /\left[\mathrm{O}_{2}(v)\right]_{B}, T_{v i b}, T_{v}$, and $T_{n}$ at $\mathrm{hmF} 2$ are presented in Fig. 4. The present study suggests that the deviations $\left[\mathrm{O}_{2}(v)\right]$ from the Boltzmann distribution of Eq. (25) are not significant at vibrational levels $v<3$, and the calculated distribution is highly non-Boltzmann at vibrational levels $v>2$. For third, forth, and fifth vibrational levels of $\mathrm{O}_{2}$ the ratios $\left[\mathrm{O}_{2}(v)\right] /\left[\mathrm{O}_{2}(v)\right]_{B}$ have their minimum values during the period 11.00-13.00 LT. The diurnal variations of the calculated $\left[\mathrm{O}_{2}(v)\right] /\left[\mathrm{O}_{2}(v)\right]_{B}$ are not significant at vibrational levels $v<3$ and the value of this ratio is about $0.98-1.11$ for $v=1$ and $0.88-0.97$ for $v=2$. From the diurnal variations of the calculated vibrational (solid line) and neutral (dashed line) temperatures shown in Fig. 4 it follows that $T_{v i b}<T_{n}$ and $T_{v}<T_{n}$ are realized in the atmosphere for the night-time periods where the

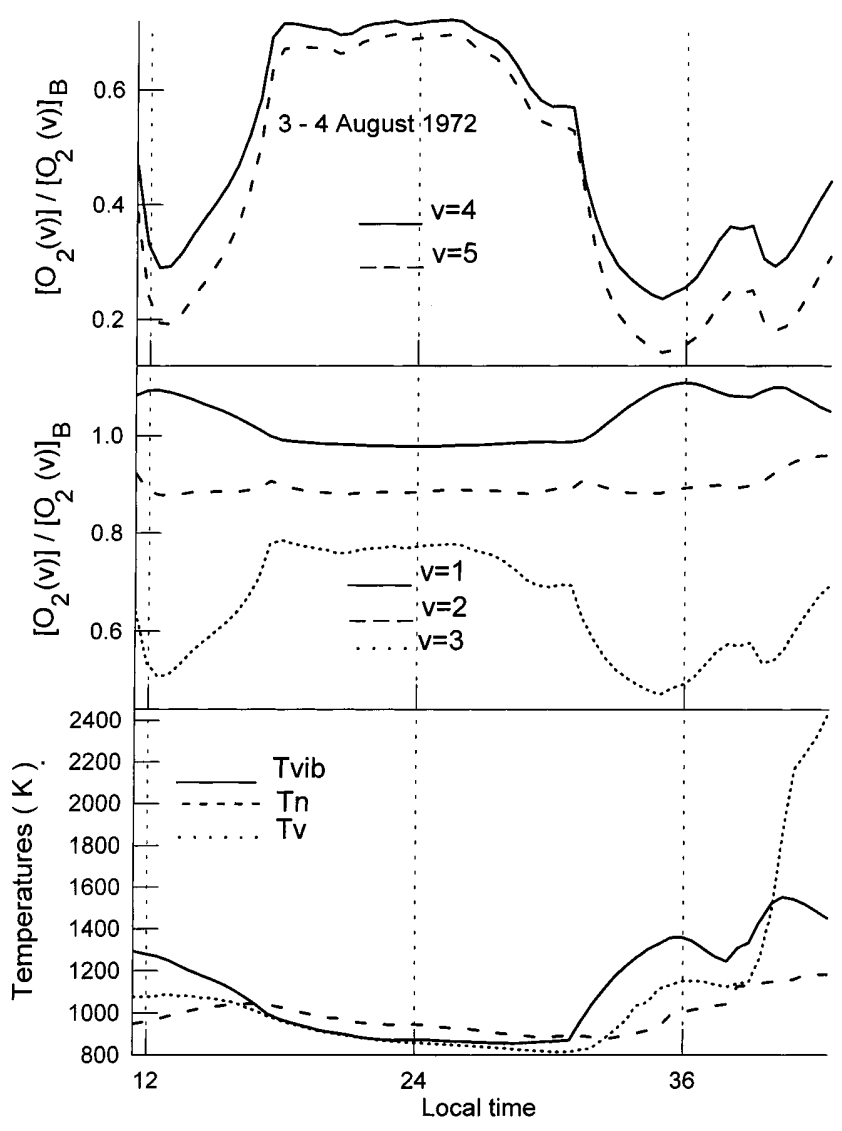

Fig. 4. The time variations of the vibrational temperatures of $\left[\mathrm{O}_{2}\right]$ and $\left[\mathrm{N}_{2}\right]$, the neutral temperature (bottom panel), and populations of the first five vibrational levels of $\mathrm{O}_{2}(v=1,2$, and 3 in the middle panel and $v=4$ and 5 in the top panel) in comparison with the Boltzmann distribution of Eq. (25) during the 3-4 August period at the F2 peak altitude. The solid lines show the modelled $T_{v i b}$, $\left[\mathrm{O}_{2}(1)\right] /\left[\mathrm{O}_{2}(1)\right]_{B}$, and $\left[\mathrm{O}_{2}(4)\right] /\left[\mathrm{O}_{2}(4)\right]_{B}$, the dashed lines show the modelled $T_{n},\left[\mathrm{O}_{2}(2)\right] /\left[\mathrm{O}_{2}(2)\right]_{B}$, and $\left[\mathrm{O}_{2}(5)\right] /\left[\mathrm{O}_{2}(5)\right]_{B}$, and the dotted lines show the modelled $T_{v}$, and $\left[\mathrm{O}_{2}(3)\right] /\left[\mathrm{O}_{2}(3)\right]_{B}$ 
production frequencies of $\mathrm{O}_{2}(v)$ and $\mathrm{N}_{2}(v)$ are low. This means that for these periods the populations of $\mathrm{O}_{2}(v)$ or $\mathrm{N}_{2}(v)$ are less than the populations for a Boltzmann distribution with temperature $T_{n}$. During the daytime $T_{v i b}$ and $T_{v}$ are larger than $T_{n}$ due to the enhanced thermal excitation of $\mathrm{O}_{2}$ and $\mathrm{N}_{2}$ as a result of high thermal electron temperatures at $\mathrm{F} 2$-region altitudes. We found that $-77 \mathrm{~K} \leq T_{v i b}-T_{n} \leq 401 \mathrm{~K}$ and $-88 \mathrm{~K} \leq$ $T_{v}-T_{n} \leq 1341 \mathrm{~K}$. On 3-4 August the value of the vibrational temperature was not more than $1555 \mathrm{~K}$ for $\mathrm{O}_{2}$ and $2539 \mathrm{~K}$ for $\mathrm{N}_{2}$. In the SAR arc regions $T_{v}$ and $T_{v i b}$ are larger than $T_{n}$ due to the enhanced thermal excitation of $\mathrm{N}_{2}$ and $\mathrm{O}_{2}$ as a result of high thermal electron temperatures at F2- region altitudes after the beginning of the increase in $T_{e}$ due to the additional heating rate of electrons.

The excitation of $\mathrm{N}_{2}$ and $\mathrm{O}_{2}$ by thermal electrons provides the main contribution to the values of $\mathrm{O}_{2}(v)$ and $\mathrm{N}_{2}(v)$ vibrational excitations (Pavlov and Namgaladze, 1988; Pavlov, 1989a, b, 1997, 1998b; Pavlov and Buonsanto, 1997). As a result, the values of $T_{v i b}-T_{n}$ and $T_{v}-T_{n}$ increase with increasing the thermal electron production frequencies, $W\left(\mathrm{O}_{2}\right)$ and $W\left(\mathrm{~N}_{2}\right)$, of the $\mathrm{O}_{2}$ and $\mathrm{N}_{2}$ vibrational quanta, correspondingly. Pavlov (1998a) found that the value of $W\left(\mathrm{~N}_{2}\right)$ increases with increasing $T_{e}$ in the temperature range 300-6000 K. As seen from Fig. 4, due to this dependence, the value of $T_{v}$ increases with increasing $T_{e}$ in the SAR arc region. The value of $W\left(\mathrm{O}_{2}\right)$ also increases with the increase of $T_{e}$ (Pavlov, 1998c). However, unlike the dependence of $W\left(\mathrm{~N}_{2}\right)$ on $T_{e}$, this increase of $W\left(\mathrm{O}_{2}\right)$ is very small in the temperature range $2500-4000 \mathrm{~K}$ as

$W\left(\mathrm{O}_{2}\right) \approx$ const $\cdot \mathrm{N}_{\mathrm{e}}$.

As seen from Eq. (26), the dependence of $T_{v i b}$ on $T_{e}$ can be neglected in the SAR arc region, and this leads to $T_{v}>T_{v i b}$. Equation (23) also explains the decrease of $T_{v i b}$ at night on 4 August as a result of day-night variations in $\mathrm{N}_{\mathrm{e}}$.

Figure 4 shows the diurnal variations of the modelled electron temperature at hmF2 (top panel), hmF2 (middle panel), and NmF2 (bottom panel) for the period 2-3 August, 1972. The top panel shows also the modelled electron temperature at $1400 \mathrm{~km}$ (dashed-dotted line) and the ISIS II spacecraft measurement of the electron temperature in the SAR arc region at 05:57:51 UT on 4 August, 1972, at $1400 \mathrm{~km}$ (cross). The solid lines show model results when vibrationally excited $\mathrm{O}_{2}$ and $\mathrm{N}_{2}$ are included in calculations of the $\mathrm{O}^{+}\left({ }^{4} S\right)$ loss rate as given by Eq. (23). The dashed lines show model results when $\mathrm{N}_{2}(v>0)$ is not included and $\mathrm{O}_{2}(v>0)$ is included in calculations of the $\mathrm{O}^{+}\left({ }^{4} S\right)$ loss rate:

$\mathrm{L}=K_{10}\left[\mathrm{~N}_{2}(v=0)\right]+\sum_{v=0}^{\infty} K_{2 v}\left[\mathrm{O}_{2}(v)\right]$.

The dotted lines in Fig. 5 are model results when the vibrationally excited nitrogen and oxygen are not included in the calculations of the loss rate the $\mathrm{O}^{+}\left({ }^{4} S\right)$ ions:

$\mathrm{L}=K_{10}\left[\mathrm{~N}_{2}(v=0)\right]+K_{20}\left[\mathrm{O}_{2}(v=0)\right]$.

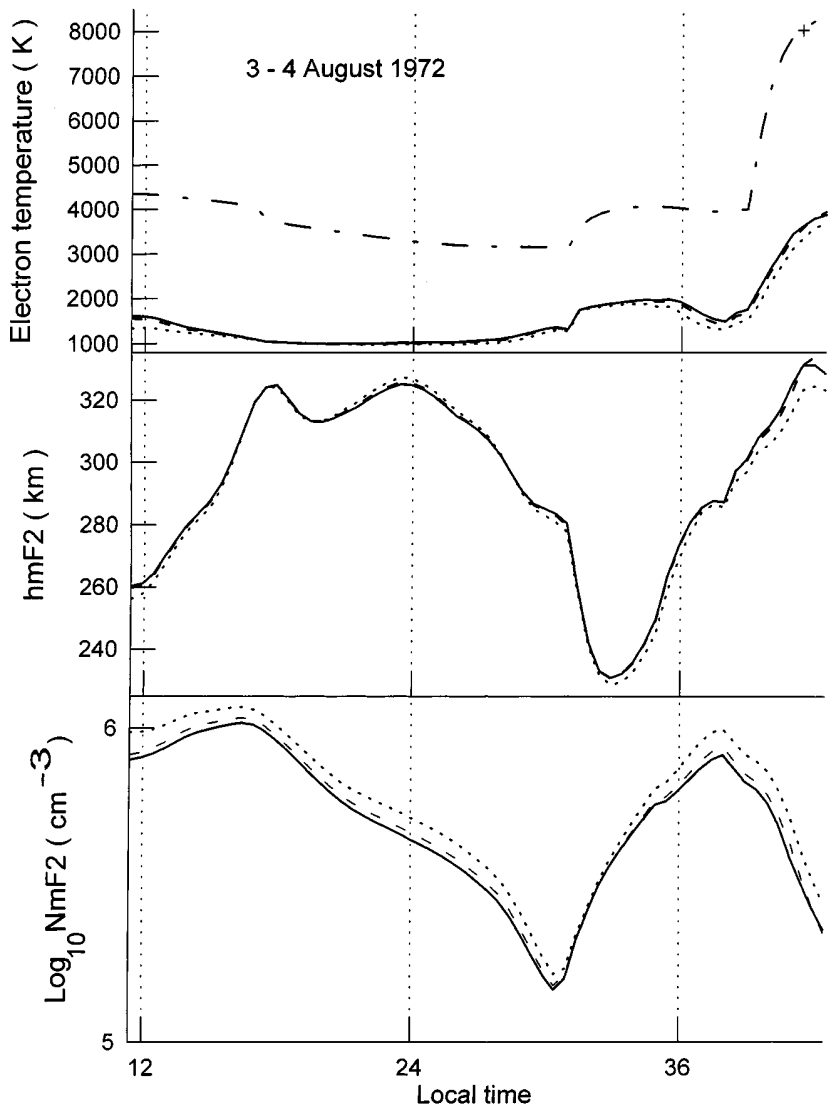

Fig. 5. The modelled $\mathrm{NmF} 2$ (bottom panel), hmF2 (middle panel), and electron temperatures at $\mathrm{hmF} 2$ and $1400 \mathrm{~km}$ (top panel) for the magnetically quiet and disturbed period 3-4 August, 1972. The modelled electron densities and temperatures were obtained with effects of $\mathrm{N}_{2}(v)$ and $\mathrm{O}_{2}(v)$ (solid lines) on the $\mathrm{O}^{+}\left({ }^{4} S\right)$ loss rate, and when $\mathrm{N}_{2}(v)$ was not included in the calculations (dashed lines) of this loss rate. The dotted lines give results without effects of $\mathrm{N}_{2}(v)$ and $\mathrm{O}_{2}(v)$ on the $\mathrm{O}^{+}\left({ }^{4} S\right)$ loss rate. The dashed-dotted line represents the calculated electron temperature at $1400 \mathrm{~km}$ altitude. The ISIS II spacecraft measurement of the electron temperature in the SAR arc region at 05:51:51 UT on 4 August, 1972, at $1400 \mathrm{~km}$ is shown by a cross

From the comparison between solid and dashed lines of Fig. 5 it follows that the increase in the $\mathrm{O}^{+}+\mathrm{N}_{2}$ loss rate due to vibrationally excited $\mathrm{N}_{2}$ produces the $5-19 \%$ reductions in the calculated quiet daytime peak density and the $16-24 \%$ decrease in NmF2 in the SAR arc region. The comparison of dashed-dotted and dashed lines show that the increase in the $\mathrm{O}^{+}+\mathrm{N}_{2}$ rate factor due to the vibrationally excited oxygen produces the $7-$ $26 \%$ decrease in the calculated quiet daytime peak density and the $12-26 \%$ decrease in NmF2 in the SAR arc region. It should be noted that there is a large increase in the modelled NmF2 without vibrationally excited $\mathrm{O}_{2}$ and $\mathrm{N}_{2}$. The resulting effect on the $\mathrm{NmF} 2$ is a factor of 1.07-1.50 decrease in the quiet night-time and daytime peak densities and a factor of 1.30-1.56 in $\mathrm{NmF} 2$ in the SAR arc region using the IZMIRAN model when vibrationally excited $\mathrm{O}_{2}$ and $\mathrm{N}_{2}$ are not included in calculations of the $\mathrm{O}^{+}\left({ }^{4} S\right)$ loss rate. The effect of vibrationally excited $\mathrm{O}_{2}$ and $\mathrm{N}_{2}$ on $\mathrm{N}_{\mathrm{e}}$ is most pronounced during the daytime. 


\subsection{Electron density and temperature in the $S A R$ arc region}

For the studied geomagnetic storm period observations exist of the electron temperature and density height profiles from the altitude of the Isis II spacecraft down to the F region (Shepherd et al., 1980). Figure 6 shows the measured (crosses) SAR arc electron densities (left panel) and temperatures (right panel) given by Shepherd et al. (1980) at 05:57:51 UT on August 4 in comparison with the modelled (lines) electron densities and temperatures. The model results were obtained with $\mathrm{N}_{2}(v)$ and $\mathrm{O}_{2}(v)$ (solid lines) and when the approaches of Eqs. (24) (dotted lines) and (25) (dashed lines) are used in the IZMIRAN model for the loss rate of the $\mathrm{O}^{+}\left({ }^{4} S\right)$ ions. When vibrationally excited nitrogen and oxygen are included in the IZMIRAN model, the agreement between the measured $\mathrm{N}_{\mathrm{e}}, T_{e}$ (crosses) and the modelled $\mathrm{N}_{\mathrm{e}}, T_{e}$ (solid lines) is good. The measured $\mathrm{N}_{\mathrm{e}}$ are higher than the modelled densities if $\mathrm{N}_{2}(v)$ or $\mathrm{O}_{2}(v)$ or $\mathrm{N}_{2}(v)$ and $\mathrm{O}_{2}(v)$ are not taken into account in calculations of the $\mathrm{O}^{+}\left({ }^{4} S\right)$ loss rate. The effects of $\mathrm{N}_{2}(v)$ and $\mathrm{O}_{2}(v)$ on the calculation of $T_{e}$ are negligible. The right panel of Fig. 6 also shows the calculated neutral temperature, and the vibrational temperatures of $\mathrm{O}_{2}$ and $\mathrm{N}_{2}$. It can been seen from a comparison of these temperatures that $T_{v}>T_{v i b}$ above $240 \mathrm{~km}$, and the neutral temperature is less than $T_{v}$ or $T_{v i b}$.
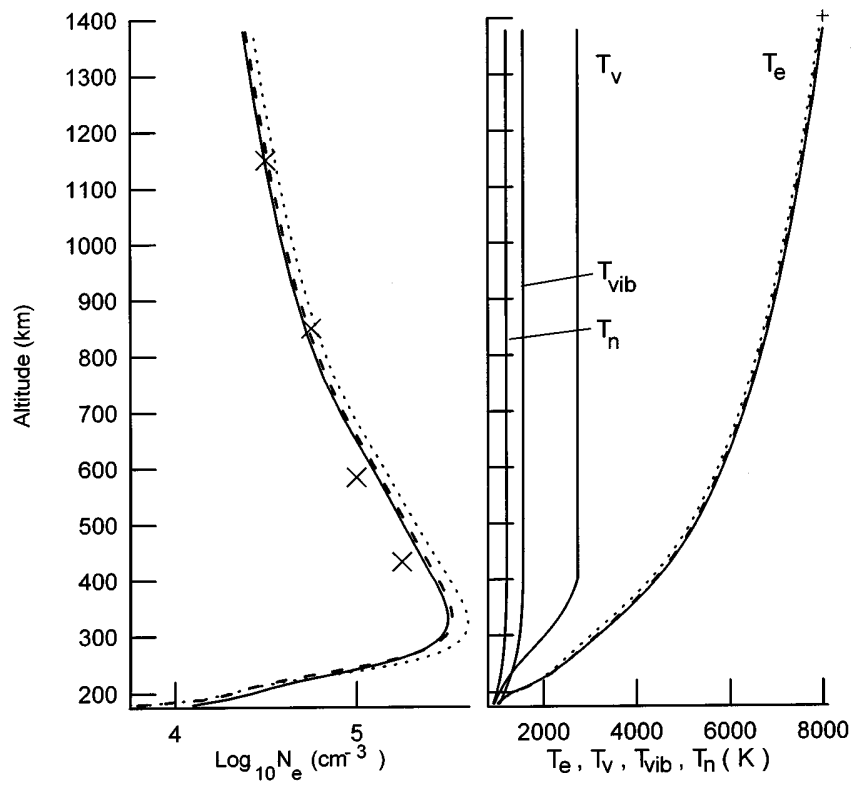

Fig. 6. Altitude profiles of the modelled (lines) electron densities (left panel) and temperatures (right panel) in the SAR arc region at 05:51:51 UT on 4 August, 1972, in comparison with the ISIS II spacecraft measurements (crosses) of the electron densities and temperatures. The modelled electron densities, $\mathrm{N}_{\mathrm{e}}$, and temperatures, $T_{e}$, were obtained with effects of $\mathrm{N}_{2}(v)$ and $\mathrm{O}_{2}(v)$ (solid lines) on the $\mathrm{O}^{+}\left({ }^{4} S\right)$ loss rate, and when $\mathrm{N}_{2}(v)$ was not included in the calculations (dashed lines) of this loss rate. The dotted lines give results without effects of $\mathrm{N}_{2}(v)$, and $\mathrm{O}_{2}(v)$ on the $\mathrm{O}^{+}\left({ }^{4} S\right)$ loss rate. The right panel shows also the vibrational temperatures, $T_{v i b}$ and $T_{v}$, of $\mathrm{O}_{2}$ and $\mathrm{N}_{2}$, and the neutral temperature, $T_{n}$, from the IZMIRAN model in the SAR arc region at 05:51:51 UT on 4 August, 1972
We found that SAR arc thermal electron heating through energy loss of the precipitating electrons is most effective in the altitude range $180-230 \mathrm{~km}$. The maximum increase of $T_{e}$ due to the electron heating rate $Q_{p r}$ is about $100 \mathrm{~K}$ at $200 \mathrm{~km}$ altitude. The energy where the fluxes of the precipitating electrons and thermal electrons cross over is less than $2 \mathrm{eV}$ below $230 \mathrm{~km}$ altitude and larger than $2 \mathrm{eV}$ above $230 \mathrm{~km}$ altitude in the region of high electron temperatures. The use of the IZMIRAN model without $Q_{p r}$ leads to negligible decreases in the calculated electron temperature $(40 \mathrm{~K}$ at $230 \mathrm{~km}$ altitude and $5 \mathrm{~K}$ at $300 \mathrm{~km}$ altitude) and total $630 \mathrm{~nm}$ integral intensity $(16 \mathrm{R})$ in the SAR arc region in comparison with $T_{e}$ and $I_{630}(0)$ calculated by using the rigorous approach with $Q_{p r}$.

\subsection{Electron cooling rates}

The relative magnitudes of the cooling rates are of particular interest for understanding the main processes which determine the electron temperature. The IZMIRAN model uses the generally accepted electron cooling rates due to electron-ion Coulomb collisions and elastic collisions of electrons with $\mathrm{N}_{2}, \mathrm{O}_{2}, \mathrm{O}, \mathrm{He}$, and $\mathrm{H}$ presented by Schunk and Nagy (1978), and the thermal electron impact excitation of $\mathrm{O}_{2}\left(a^{1} \Delta_{g}\right)$ and $\mathrm{O}_{2}\left(b^{1} \Sigma_{g}^{+}\right)$ given by Prasad and Furman (1973). The cooling rates of electrons which are in general use (see Schunk and Nagy, 1978) are the thermal electron impact excitation of the fine structure levels of the ground state of atomic oxygen of Hoegy (1976), the electron cooling rates given by Stubbe and Varnum (1972) and Prasad and Furman (1973) for vibrational excitation of $\mathrm{N}_{2}$ and $\mathrm{O}_{2}$, the rate of electron cooling through rotational excitation of $\mathrm{N}_{2}$ and $\mathrm{O}_{2}$ presented by Stubbe and Varnum (1972) and Dalgarno et al. (1968), and the electron energy loss arising from electron-impact-induced transitions ${ }^{3} P \rightarrow{ }^{1} D$ for atomic oxygen of Stubbe and Varnum (1972).

Pavlov (1998a, c) calculated and fit to the new analytical expressions the electron cooling rates by rotational and vibrational excitation of $\mathrm{N}_{2}$ and $\mathrm{O}_{2}$ using the revised quadrupole moments of $\mathrm{O}_{2}$ and $\mathrm{N}_{2}$ averaged over the ground vibrational state of $\mathrm{O}_{2}$ and $\mathrm{N}_{2}$, and the revised vibrationally excited $\mathrm{O}_{2}$ and $\mathrm{N}_{2}$ cross sections, and these new electron cooling rates were used in the IZMIRAN model of Pavlov (1998b). Pavlov and Berrington (1999) used the theoretical $\mathrm{O}\left({ }^{3} P\right)$ excitation cross sections of Bell et al. (1998) to calculate and to fit to a new analytical expression for atomic oxygen fine structure cooling rate of thermal electrons, and this new approach is included in the updated IZMIRAN model. At the $\mathrm{F}$ region altitudes of the ionosphere, this new cooling rate is less than the currently accepted fine structure cooling rate of Hoegy (1976) by a factor of 2 4 , and this cooling is not the dominant electron cooling process in the $\mathrm{F}$ region of the ionosphere at middle latitudes (Pavlov and Berrington, 1999). The revised IZMIRAN model cooling due to electronic excitation of $\mathrm{O}\left({ }^{1} D\right)$ is given by Eq. (5). 
The solid lines in Fig. 6 show a comparison of the IZMIRAN model electron cooling rates with the currently accepted cooling rates (dashed lines) in the studied SAR arc region at 05:51:51 UT on 4 August 1972. The energy exchange between the electron and ion gases (curve 1), the revised electron cooling rates due to excitation of $\mathrm{O}$ to the ${ }^{1} D$ state (curve 4 ), and by vibrational excitation of $\mathrm{N}_{2}$ (curve 2) and $\mathrm{O}_{2}$ (curve 3) are the dominant cooling channels above $200 \mathrm{~km}$. The IZMIRAN model fine structure cooling by $\mathrm{O}$ (curve 5) and the electron cooling rate by rotational excitation of $\mathrm{N}_{2}$ (curve 6) are much less than the mentioned cooling rates in the SAR arc region. We found that the contribution of the cooling of electrons by low-lying electronic excitation of $\mathrm{O}_{2}\left(a^{1} \Delta_{g}\right)$ and $\mathrm{O}_{2}\left(b^{1} \Sigma_{q}^{+}\right)$(curve 8 ), and the revised cooling by rotational excitation of $\mathrm{O}_{2}$ (curve 7) can be neglected above $200 \mathrm{~km}$ altitude as they are not more than $1 \%$ of the total cooling rate during the quiet and geomagnetic storm period 3-4 August, 1972. The cooling of electrons due to total elastic electron-neutral collisions (curve 9) varies between $1 \%$ to $5 \%$ of the total cooling rate in the altitude range 200 $700 \mathrm{~km}$ and can be considered small in the ionosphere in comparison with the total cooling rate (curve 10).

The dashed lines of Fig. 7 show the calculated cooling rates $\mathrm{L}\left(\mathrm{O}\left({ }^{3} P_{j}\right)\right), \quad \mathrm{L}\left(\mathrm{O}\left({ }^{1} D\right)\right), \quad \mathrm{L}\left(\mathrm{N}_{2}(v)\right), \quad \mathrm{L}\left(\mathrm{O}_{2}(v)\right)$, $\mathrm{L}\left(\mathrm{N}_{2}(\right.$ rot $\left.)\right)$, and $\mathrm{L}\left(\mathrm{O}_{2}(\right.$ rot $\left.)\right)$ of electrons due to the excitation of fine structure levels in $\mathrm{O}$, electron-impactinduced transitions ${ }^{3} P \rightarrow{ }^{1} D$ for atomic oxygen, vibrational excitation of $\mathrm{N}_{2}$ and $\mathrm{O}_{2}$, and rotational excitation of $\mathrm{N}_{2}$ and $\mathrm{O}_{2}$ which are currently used in models of the ionosphere (Schunk and Nagy, 1978). It is clear from Fig. 7 that the IZMIRAN model value of $\mathrm{L}\left(\mathrm{O}\left({ }^{1} D\right)\right.$ ) (solid line 4) is lower than those of Stubbe and Varnum (1972) (dashed line 4) by a factor of 1.2-2.6 in the height range $260-600 \mathrm{~km}$. The ratio of the IZMIRAN model $\mathrm{L}\left(\mathrm{O}_{2}(v)\right)$ (solid line 3 ) to $\mathrm{L}\left(\mathrm{O}_{2}(v)\right)$ given by Prasad and Furman
(1973) (dashed line 3) is about $2-7$ in the region between 200 and $500 \mathrm{~km}$ in altitude. The IZMIRAN model $\mathrm{L}\left(\mathrm{N}_{2}(v)\right.$ ) (solid line 2) is higher than those of Stubbe and Varnum (1972) (dashed line 2) by a factor of 3-6 below $220 \mathrm{~km}$ and only up to a factor of 1.4 in the altitude range $230-500 \mathrm{~km}$. The ratio of the generally accepted $\mathrm{L}\left(\mathrm{O}\left({ }^{3} P_{j}\right)\right)$ given by Hoegy (1976) (dashed line 5) to $\mathrm{L}\left(\mathrm{O}\left({ }^{3} P_{j}\right)\right)$ given by Pavlov and Berrington (1999) (solid line 5) is about 2-6 in the region between 200 and $700 \mathrm{~km}$ in altitude.

It was shown that the rate of electron energy loss associated with rotational transitions in $\mathrm{N}_{2}$ of Stubbe and Varnum (1972) must be multiplied by a factor of 1.255 (Pavlov, 1998a), and the rate of electron energy loss associated with rotational transitions in $\mathrm{O}_{2}$ given by Dalgarno et al. (1968) must be decreased by a factor of 13 (Pavlov, 1998c). These ratios determine the difference between the IZMIRAN model electron cooling rates due to rotational excitation of $\mathrm{N}_{2}$ (solid line 6 of Fig. 7) and $\mathrm{O}_{2}$ (solid line 7 of Fig. 7) and those of Stubbe and Varnum (1972) (dashed line 6 of Fig. 7) and Dalgarno et al. (1968) (dashed line 7 of Fig. 7) which are in general use.

The electron temperature is determined from the electron energy balance by competition between total heating, cooling, and energy flow processes. To calculate the total cooling rate of thermal electrons, it is necessary to sum up all energy loss rates mentioned for electrons. The ratio of the resulting IZMIRAN model total cooling rate (solid line 10 of Fig. 7) to the generally accepted total cooling rate of Schunk and Nagy (1978) (dashed line 10 of Fig. 7) is about $0.8-1.4$ in the SAR arc region between 200 and $700 \mathrm{~km}$ in altitude.

\section{Conclusions}

The comparison of the measurements of the electron density and temperature, the integral airglow intensity

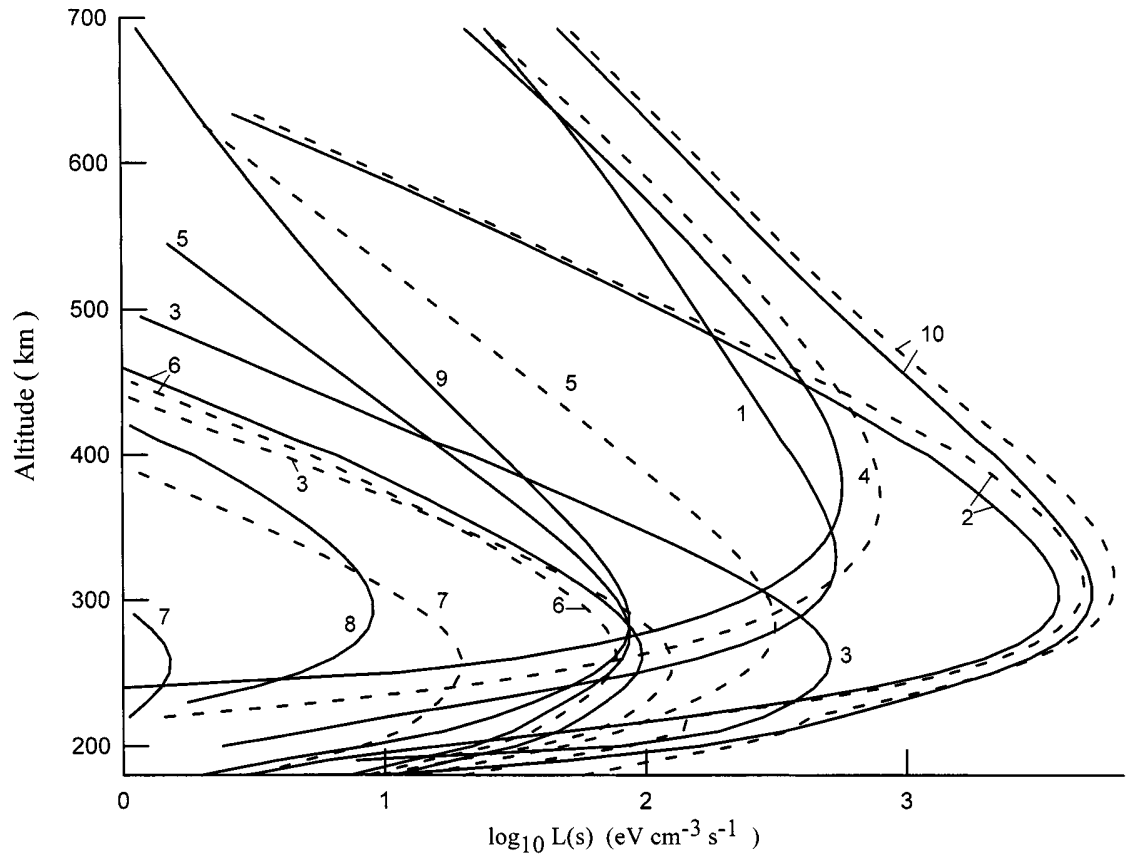

Fig. 7. The IZMIRAN model (solid lines) and generally accepted (dashed lines) altitude profiles of electron cooling rates, $\mathrm{L}(\mathrm{s})$, in the SAR arc region at 05:51:51 UT on 4 August, 1972. Line 1 gives the cooling due to Coulomb collisions electrons with ions. The cooling rates by vibrational excitation of $\mathrm{N}_{2}$ and $\mathrm{O}_{2}$ are shown by curves 2 and 3. Lines 4 represent the electron cooling rate in collision of $\mathrm{O}\left({ }^{3} P\right)$ with thermal electrons with the $\mathrm{O}\left({ }^{1} D\right)$ formation. Lines 5 show the electron cooling rates due to collisions of electrons with atomic oxygen which excite fine structure transitions among the ground state levels of atomic oxygen. The cooling rates by rotational excitation of $\mathrm{N}_{2}$ and $\mathrm{O}_{2}$ are shown by curves 6 and 7. Line 8 gives the cooling due to the thermal electron impact excitation of $\mathrm{O}_{2}\left(a^{1} \Delta_{g}\right)$ and $\mathrm{O}_{2}\left(b^{1} \Sigma_{g}^{+}\right)$, and the total elastic cooling rate by elastic collisions of electrons with $\mathrm{N}_{2}, \mathrm{O}_{2}, \mathrm{O}, \mathrm{He}$, and $\mathrm{H}$ is shown by curve 9. Lines 10 represent the total cooling rates of electrons 
and volume emission rate at $630 \mathrm{~nm}$ in the SAR arc region, which were obtained on the Isis II spacecraft on 4 August 1972, with the model results is presented. The model used is an enhanced version of the IZMIRAN model we have steadily developed over the years. The major enhancement to the IZMIRAN model developed in this study is the use of the analytical yield spectrum approach developed by Green et al. (1977), Jackman and Green (1979), Singhal et al. (1979), Singhal and Green (1981), and Haider and Singhal (1983) to calculate the fluxes of precipitating electrons in the altitude range $120-1000 \mathrm{~km}$ in the Northern and Southern Hemispheres if an incident electron flux is given at the upper boundary. Using this approach the IZMIRAN model calculates the additional production rates of $\mathrm{N}_{2}^{+}, \mathrm{O}_{2}^{+}, \mathrm{O}^{+}\left({ }^{4} S\right), \mathrm{O}^{+}\left({ }^{2} D\right), \mathrm{O}^{+}\left({ }^{2} P\right)$, and $\mathrm{O}^{+}\left({ }^{2} P\right)$ ions, $\mathrm{O}\left({ }^{1} D\right), \mathrm{N}_{2}\left(C^{3} \Pi_{u}, n\right), \mathrm{N}_{2}\left(B^{3} \Pi_{g}^{+}, i\right), \mathrm{N}_{2}\left(A^{3} \Sigma_{u}^{+}, j\right)$, and $\mathrm{O}\left({ }^{1} S\right)$, and the additional thermal electron heating in the SAR arc regions in the Northern and Southern Hemispheres due to fluxes of precipitating electrons. In order to bring the measured and modelled electron temperatures into agreement, the additional heating electron rate of $1.05 \mathrm{eV} \mathrm{cm}^{-3} \mathrm{~s}^{-1}$ providing the heat flux to the SAR-arc region was added to the energy balance equation of electrons at the altitude above $5000 \mathrm{~km}$ during the main phase of the geomagnetic storm.

We found that the best agreement between the modelled and measured volume emission rates at $630 \mathrm{~nm}$ is obtained if the approach of $F_{\infty}(E)=$ $0.2 U(E)$ for the incident electron flux at $1000-\mathrm{km}$ altitude is used during all storm time period where $U(E)$ is the value of the measured spectra at the pitch angle of $31^{\circ}$ at 05:57:51 UT. The IZMIRAN model calculates the $630 \mathrm{~nm}$ integral intensity above $350 \mathrm{~km}$ of $4.1 \mathrm{kR}$ and the total $630 \mathrm{~nm}$ integral intensity of $8.1 \mathrm{kR}$, which are slightly lower compared to $4.7 \mathrm{kR}$ and $10.6 \mathrm{kR}$ that were observed by Shepherd et al. (1980). We conclude that the comparison between the measured and modelled $630 \mathrm{~nm}$ emissions indicates that our model reproduces major features of the data. The $630 \mathrm{~nm}$ emission observed can be explained taking into account both the soft energy electron excited component and the thermally excited component.

The deviations from the Boltzmann distribution for the first five vibrational levels of $\mathrm{O}_{2}$ were calculated. The present study suggests that the deviations from the Boltzmann distribution are not significant. The calculations also showed that the $\mathrm{O}_{2}$ and $\mathrm{N}_{2}$ vibrational temperatures during the quiet periods are less than during the magnetic storm periods. During the daytime the high vibrational temperatures stem from the enhanced thermal excitation of $\mathrm{O}_{2}$ and $\mathrm{N}_{2}$ as a result of high thermal electron temperatures at F2-region altitudes, while the decrease in the vibrational temperatures compared to the regular temperature is due to the decreases in the electron density and the neutral temperature.

We found that the inclusion of $\mathrm{N}_{2}(v>0)$ and $\mathrm{O}_{2}(v>0)$ in the calculations of the $\mathrm{O}^{+}\left({ }^{4} S\right)$ loss rate improves the agreement between the calculated $\mathrm{N}_{\mathrm{e}}$ and the data on 4 August, 1972 and the $\mathrm{N}_{2}(v>0)$ and
$\mathrm{O}_{2}(v>0)$ effects are enough to explain the electron density depression in the SAR arc F-region and above F2 peak altitude. Our calculations show that the increase in the $\mathrm{O}^{+}+\mathrm{N}_{2}$ rate factor due to the vibrationally excited nitrogen produces the $5-19 \%$ reductions in the calculated quiet daytime peak density and the 16$24 \%$ decrease in $\mathrm{NmF} 2$ in the SAR arc region. The increase in the $\mathrm{O}^{+}+\mathrm{N}_{2}$ loss rate due to vibrationally excited $\mathrm{O}_{2}$ produces the $7-26 \%$ decrease in the calculated quiet daytime peak density and the 12-26\% decrease in $\mathrm{NmF} 2$ in the SAR arc region. The effect of vibrationally excited $\mathrm{O}_{2}$ and $\mathrm{N}_{2}$ on $\mathrm{N}_{\mathrm{e}}$ is most pronounced during the daytime.

The electron energy balance has been studied by employing the revised energy loss rates. We evaluated the role of the electron cooling rates by low-lying electronic excitation of $\mathrm{O}_{2}\left(a^{1} \Delta_{g}\right)$ and $\mathrm{O}_{2}\left(b^{1} \Sigma_{g}^{+}\right)$, and rotational excitation of $\mathrm{O}_{2}$, and found that the effect of these cooling rates on $T_{e}$ can be considered negligible above $200 \mathrm{~km}$ altitude during the quiet and geomagnetic storm period 3-4 August, 1972. The energy exchange between electron and ion gases, the cooling rate in collisions of $\mathrm{O}\left({ }^{3} P\right)$ with thermal electrons with excitation of $\mathrm{O}\left({ }^{1} D\right)$, and the electron cooling rates by vibrational excitation of $\mathrm{N}_{2}$ and $\mathrm{O}_{2}$ and are the largest cooling rates above $200 \mathrm{~km}$ in the SAR arc region on 4 August, 1972.

The enhanced IZMIRAN model used for this study calculates number densities of $\mathrm{N}_{2}\left(B^{3} \Pi_{g}^{+}, i\right)$, $\mathrm{N}_{2}\left(C^{3} \Pi_{u}, n\right), \mathrm{N}_{2}\left(A^{3} \Sigma_{u}^{+}, j\right)$, and $\mathrm{O}\left({ }^{1} S\right)$, and the volume emission rate and integral intensity at $557.7 \mathrm{~nm}$ in the region between 120 and $1000 \mathrm{~km}$ in altitude in the SAR arc region on 4 August, 1972. We found that the excitation process producing $\mathrm{O}\left({ }^{1} S\right)$ directly, electron impact on ambient $\mathrm{O}\left({ }^{3} P\right)$, and the reaction of $\mathrm{N}_{2}\left(A^{3} \Sigma_{u}^{+}\right)$ and $\mathrm{O}\left({ }^{3} P\right)$ are the dominant production mechanisms for $\mathrm{O}\left({ }^{1} S\right)$ below about $480 \mathrm{~km}$, and the interaction between $\mathrm{N}_{2}\left(A^{3} \Sigma_{u}^{+}, j\right)$ and $\mathrm{O}\left({ }^{3} P\right)$ is the dominant production source of $\mathrm{O}\left({ }^{1} S\right)$ at altitudes less than $190 \mathrm{~km}$. We found also that the production rate of $\mathrm{O}\left({ }^{1} S\right)$ following the dissociation of $\mathrm{O}_{2}$ by precipitating electrons can be neglected in comparison with other sources of $\mathrm{O}\left({ }^{1} S\right)$. One of the main properties of SAR arcs is that their dominant spectral line is the $630 \mathrm{~nm}$ line of atomic oxygen. Our results shown that $I_{557.7}(z)<<I_{630}(z)$ in agreement with a classical SAR-arc property.

Acknowledgements. The research described in this publication was supported by grants 96-05-64031 and 99-05-65231 from the Russian Foundation for Basic Research. We would like to thank all referees for critical reading of the manuscript as reviewers and for helpful comments.

The Editor in Chief thanks J. Lilensten, G. Bailey and J. Kozyra for their help in evaluating this paper.

\section{Appendix}

Model of precipitating electron fluxes

To calculate an equilibrium electron flux in the Earth's atmosphere we use the analytical spatial yield approach developed by Haider and Singhal (1983). Although they considered the spatial yield spectra for electron energy degradation in the non-homogeneous 
atmosphere, some formulas in their paper are valid only in the case of homogeneous gas mixtures. Because the generalization of this relationships maybe not so evident, as well as for consistency within the present work, we reproduce here some formulas for calculations of electron fluxes, where the non-homogeneity of the atmosphere is taken into account in the explicit form.

Assuming that velocities of electrons are directed along the magnetic field line and an incident electron flux, $F_{\infty}(E)$, is given as an upper boundary condition, the flux of precipitating electrons is calculated by Haider and Singhal (1983) in the energy range $2 \mathrm{eV}-10 \mathrm{keV}$ as

$F(E, s)=\frac{\rho(s)}{\sum_{k} n_{k}(s) \sigma_{k}(E)} \int_{E_{\min }}^{E_{\max }} U^{c}\left(E, z\left(s, E_{0}\right), E_{0}\right) F_{\propto}\left(E_{0}\right) d E_{0}$,

where $s$ is the distance along the magnetic field line from the upper boundary expressed in $\mathrm{cm}, \rho$ is the mass density of the atmosphere expressed in $\mathrm{gm} \mathrm{cm}{ }^{-3}, n_{k}$ denotes the number density of the $k$-th neutral component of the atmosphere, the unit of $n_{k}$ is $\mathrm{cm}^{-3}, E_{\min }$ and $E_{\max }$ are the boundaries of the energy range for incident electrons in $\mathrm{eV}, \sigma_{k}$ is the total inelastic cross section of the $k$-th neutral component of the atmosphere expressed in $\mathrm{cm}^{-2}, z$ is an "effective" distance $\left(\mathrm{gm} \mathrm{cm}^{-2}\right)$, and $U^{c}$ is a composite threedimensional yield spectrum $\left(\mathrm{eV}^{-1} \mathrm{gm}^{-1} \mathrm{~cm}^{2}\right)$, the units of $F$ and $F_{\infty}$ are $\mathrm{cm}^{-2} \mathrm{~s}^{-1} \mathrm{eV}^{-1}$.

An "effective" distance, $z$, depends on the energy of incident electrons and is calculated as

$z\left(s, E_{0}\right)=\int_{0}^{s} d s^{\prime} \rho\left(s^{\prime}\right) / \bar{R}\left(E_{0}, s^{\prime}\right)$.

An effective scaling factor $\bar{R}$ in Eq. (A2) is given by

$\bar{R}\left(E_{0}, s\right)=\frac{\sum_{k} n_{k}(s) Z_{k}^{\prime}\left(E_{0}\right) R_{k}\left(E_{0}\right)}{\sum_{k} n_{k}(s) Z_{k}^{\prime}\left(E_{0}\right)}$,

where $R_{k}$ is a scaling factor for $k$-th neutral component.

It should be noted that a scaling factor $\bar{R}$ depends only on ratios of $Z_{k}^{\prime} / Z_{1}^{\prime}$. As a result, it is possible to assume that $Z_{1}^{\prime}\left(E_{0}\right)=1$ for some neutral component ( $\mathrm{N}_{2}$ in our calculations) and calculate $Z_{k}^{\prime}\left(E_{0}\right)$ for other neutral components as

$Z_{k}^{\prime}\left(E_{0}\right)=\frac{Z_{1}^{\prime}\left(E_{0}\right)}{E_{0}-E_{m}} \int_{E_{m}}^{E_{0}} \frac{\sigma_{T k}(E)}{\sigma_{T 1}(E)} d E$,

where $\sigma_{T k}$ is the total (elastic + inelastic) cross section of gas " $k$ ", $E_{m}$ is the minimum threshold energy for the states considered (in our calculations we assume $E_{m} \approx 0 \mathrm{eV}$ ).

Singhal et al. (1980) and Singhal and Green (1981) give analytical formulas to calculate values of $R_{k}$ for molecular nitrogen and atomic oxygen (see also the paper by Haider and Singhal, 1983, for correct values of constants for atomic oxygen). A scale factor for molecular oxygen can be found from the relationship of Haider and Singhal (1983) as

$\frac{R_{\mathrm{O}_{2}}\left(E_{0}\right)}{R_{\mathrm{N}_{2}}\left(E_{0}\right)}=\frac{m_{\mathrm{O}_{2}}}{m_{\mathrm{N}_{2}}} \frac{Z_{\mathrm{N}_{2}}\left(E_{0}\right)}{Z_{\mathrm{O}_{2}}\left(E_{0}\right)}$

Composite yield function is defined in terms of "partial" yield functions, $U_{k}$, for each component of gas mixture as

$U^{c}\left(E, z, E_{0}\right)=\frac{\sum_{k} n_{k}(s) Z_{k}\left(E_{0}\right) U_{k}\left(E_{0}, z\left(E_{0}, s\right)\right)}{\sum_{k} n_{k}(s) Z_{k}\left(E_{0}\right)}$.

It should be noted that composite yield function depends only on ratios of $Z_{k} / Z_{1}$. As a result, it is possible to assume that $Z_{1}\left(E_{0}\right)=1$ for some neutral component ( $\mathrm{N}_{2}$ in our calculations) and calculate $Z_{k}\left(E_{0}\right)$ for other neutral components as

$Z_{k}\left(E_{0}\right)=\frac{Z_{1}\left(E_{0}\right)}{E_{0}-E_{m}} \int_{E_{m}}^{E_{0}} \frac{\sigma_{k}(E)}{\sigma_{1}(E)} d E$,

where $\sigma_{k}$ and $\sigma_{1}$ are inelastic cross sections for $k$-th and 1st components.
Analytical formulas for partial yield functions in Eq. (A6) for molecular nitrogen and atomic oxygen are given by Singhal et al. (1980) and Singhal and Green (1981). In constructing a partial yield function for molecular oxygen we use the parameters for partial molecular nitrogen yield function as suggested by Haider and Singhal (1983).

For $\mathrm{O}$, the elastic cross section employed in the electron transport code was drawn from the work of Williams and Allen (1989) for energies below $8.7 \mathrm{eV}$, and, above $8.7 \mathrm{eV}$, we have adopted the elastic cross section of Joshipura and Patel (1993) up to $1 \mathrm{keV}$. The integral cross section of Doering and Gulcicek (1989) for electron collisional excitation of the ${ }^{3} P \rightarrow{ }^{1} D$ transition in atomic oxygen is a part of the total inelastic cross section for $\mathrm{O}$ presented by Laher and Gilmore (1990). We use the total inelastic cross section of Laher and Gilmore (1990) which is changed by taking into account the revised cross section for the ${ }^{3} P \rightarrow{ }^{1} D$ transition measured by Doering (1992).

For $\mathrm{O}_{2}$, the total elastic and inelastic cross sections are taken from Kanic et al. (1993) below $1 \mathrm{keV}$. The $\mathrm{N}_{2}$ elastic cross section of Iticawa (1994) for electron energies below $1 \mathrm{keV}$ is used in our model. The $\mathrm{N}_{2}$ total inelastic cross section is given by Majed and Strickland (1997) below $1 \mathrm{keV}$ and we employ this cross section with some modification. The $\mathrm{N}_{2}$ vibrational excitation cross sections used by Majed and Strickland (1997) in calculations of the $\mathrm{N}_{2}$ total inelastic cross section were replaced by the $\mathrm{N}_{2}$ vibrational excitation cross sections of Robertson et al. (1997) for vibrational levels $v=1$ and 2, and those of Schulz (1976) for $v=3$ 10 with the normalization factor of 0.7 given by Haddad (1984) (see details in Pavlov, 1998a).

Note that for electron impact energy $E>1000 \mathrm{eV}$ we approximate the total elastic and inelastic cross sections with the formulas of Born-Bethe theory given by Laher and Gilmore (1990) for O and Liu (1987) for $\mathrm{N}_{2}$ and $\mathrm{O}_{2}$

\section{References}

Albritton, D. L., I. Dotan, W. Lindinger, W. McFarland, J. Tellinghuisen, and F. C. Fehsenfeld, Effects of ion speed distributions in flow-drift tube studies of ion-neutral reactions, J. Chem. Phys. 66, 410-421, 1977.

Banks, P. M., C. R. Chappel, and A. F. Nagy, A new model for the interaction of auroral electrons with the atmosphere: spectral degradation, backscatter, optical emission, and ionization, J. Geophys. Res., 79, 1459-1470, 1974.

Bell, K. L., K. A. Berrington, and M. R. J. Thomas, Electron impact excitation of the ground-state ${ }^{3} \mathrm{P}$ fine-structure levels in atomic oxygen, Mon. Not. R. Astron. Soc. 293, L83-L87, 1998.

Bhatia, A. K., and S. O. Kastner, The neutral oxygen spectrum. I. Collisionally excited level populations and line intensities under optically thin conditions, Astrophys. J. Suppl. Ser., 96, 325-341, 1995.

Dalgarno, A., M. B. McElroy, and J. C. G. Walker, The effect of oxygen cooling on ionospheric electron temperatures, Planet. Space Sci., 16, 1371-1380, 1968.

De Benedicctis, S., and G. Dilecce, Rate constants for deactivation of $\mathrm{N}_{2}(A) v=2-7$, J. Chem. Phys., 107, 6219-6229, 1997.

Doering, J. P., Absolute differential and integral electron excitation cross-sections for atomic oxygen. 9. Improved cross sections for the ${ }^{3} P \rightarrow{ }^{1} D$ transition from 4.0 to $30 \mathrm{eV}, J$. Geophys. Res., 97 , 19 531-19 534, 1992.

Doering, J. P., and E. E. Gulcicek, Absolute differential and integral electron excitation cross- sections for atomic oxygen. 7. The ${ }^{3} \mathrm{P} \rightarrow{ }^{1} \mathrm{D}$ and ${ }^{3} \mathrm{P} \rightarrow{ }^{1} \mathrm{~S}$ transitions from 4.0 to $30 \mathrm{eV}, J$. Geophys. Res., 94, 1541-1546, 1989.

Foster, J. C., M. J. Buonsanto, M. Mendillo, D. Nottingham, F. J. Rich, and W. Denig, Coordinated stable auroral red arc observations: relationship to plasma convection, J. Geophys. Res., 99, 11 429-11 439, 1994. 
Gattinger, R. L., F. R. Harris, and A. Vallance Jones, The height, spectrum and mechanism of type-B red aurora and its bearing on the excitation of $\mathrm{O}\left({ }^{1} \mathrm{~S}\right)$ in aurora, Planet. Space Sci., 33, 207215,1985

Gilmore, F. G., R. R. Laher, and P. J. Espy, Frank-Condon factors, r-centroids, electronic transition moments, and Einstein coefficients for many nitrogen and oxygen band systems, J. Phys. Chem. Ref. Data, 21, 1005-1107, 1992.

Green, A. E. S., C. H. Jackman, and R. H. Garvey, Electron impact on atmospheric gases. 2. Yield spectra, J. Geophys. Res., 82, 5104-5111, 1977

Gurgiolo, C., D. W. Slater, J. D. Winningham, and J. L. Burch, Observation of a heated electron population associated with the 6300 A SAR arc emission, Geophys. Res. Lett., 9, 965-968, 1982.

Haddad, G. N., Cross sections for electron scattering in nitrogen, Austr. J. Phys., 37, 484-494, 1984.

Haider, S. A., and R. P. Singhal, Analytical yield spectrum approach to electron energy degradation in Earth's atmosphere, J. Geophys. Res., 88, 7185-7189, 1983.

Hasting, J. T., and R. G. Roble, An automatic technique for solving coupled vector systems of non-linear parabolic partial differential equations in one space dimension, Planet. Space. Sci., 25, 209-215, 1977.

Hierl, M. P., I. Dotan, J. V. Seeley, J. M. Van Doren, R. A. Morris, and A. A. Viggiano, Rate constants for the reactions of $\mathrm{O}^{+}$with $\mathrm{N}_{2}$ and $\mathrm{O}_{2}$ as a function of temperature (300-1800 K), J. Chem. Phys., 106, 3540-3544, 1997.

Hedin, A. E., MSIS-86 thermospheric model, J. Geophys. Res., 92, 4649-4662, 1987.

Hoegy, W. R., New fine structure cooling rate, Geophys. Res. Lett., 3, 541-544, 1976.

Hoffman, R. A., L. J. Cahll, Jr., R. R. Anderson, N. C. Maynard, P. H. Smith, T. A. Fritz, D. J. Williams, A. Konradi, and D. A. Gurnett, Explorer $45\left(\mathrm{~S}^{3}-\mathrm{A}\right)$ observations of the magnetosphere and magnetopause during the August 4-6, 1972, magnetic storm period, J. Geophys. Res., 80, 4287-4296, 1975.

Hwang, W., Y. -K. Kim, and M. E. Rudd, New model for electronimpact ionization cross sections of molecules, J. Chem. Phys., 104, 2956-2966, 1996

Itikawa, Y., Electron collisions with $\mathrm{N}_{2}, \mathrm{O}_{2}$, and $\mathrm{O}$ : what we do and not know, in Advances in Atomic, Molecular and Optical Physics, 33, Academic Press, New York, 253-273, 1994.

Jackman, C. H., and A. E. S. Green, Electron impact on atmospheric gases. 3. Spatial yield spectra for $\mathrm{N}_{2}, J$. Geophys. Res., 84, 2715-2724, 1979.

Joshipura, K. N., and P. M. Patel, Cross sections of $\mathrm{e}^{-}-\mathrm{O}$ scattering at intermediate and high energies $\left(\mathrm{E}_{\mathrm{i}}=8.7-1000 \mathrm{eV}\right)$, Phys. Rev., 48, 2464-2467, 1993.

Kanic, I., S. Trajmar, and J. C. Nickel, Total electron scattering and electronic state excitations cross sections for $\mathrm{O}_{2}, \mathrm{CO}_{2}$, and $\mathrm{CH}_{4}$, J. Geophys. Res., 98 E, 7447-7460, 1992.

Kozyra, J. U., A. F. Nagy, and D. W. Slater, High-altitude energy source(s) for stable auroral red arcs, Rev. Geophys., 35, 155-190, 1997.

Laher, R. R., and F. R. Gilmore, Updated excitation and ionization cross sections for electron impact on atomic oxygen, J. Phys. Chem. Ref. Data, 19, 277-305, 1990.

LaValle, S. R., and D. D. Elliott, Observations of SAR arcs from OV1-10, J. Geophys. Res., 77, 1802-1809, 1972.

LeClair, L. R., and J. W. McConkey, Selective detection of $\mathrm{O}\left({ }^{1} \mathrm{~S}_{0}\right)$ following electron impact dissociation of $\mathrm{O}_{2}$ and $\mathrm{N}_{2} \mathrm{O}$ using a $\mathrm{XeO}^{*}$ conversion technique, J. Chem. Phys., 99, 4566-4577, 1993.

Liu, J. W., Total cross sections for high-energy electron scattering by $\mathrm{H}_{2}\left({ }^{1} \Sigma_{\mathrm{g}}^{+}\right), \mathrm{N}_{2}\left({ }^{1} \Sigma_{\mathrm{g}}^{+}\right)$, and $\mathrm{O}_{2}\left({ }^{3} \Sigma_{\mathrm{g}}^{-}\right)$, Phys. Rev. A, 35, 591-597, 1987.

Lummerzheim, D., and J. Lilensten, Electron transport and energy degradation in the ionosphere: evaluation of the numerical solution, comparison with laboratory experiments and auroral observations, Ann. Geophysicae, 12, 1039-1051, 1994.
Majeed, T., and D. J. Strickland, New survey of electron impact cross sections for photoelectron and auroral electron energy loss calculations, J. Phys. Chem. Ref. Data, 26, 335-349, 1997.

Maier, E. J., S. Chandra, L. Brace, L. et al. The SAR arc event observed during the December 1971 magnetic storm, J. Geophys. Res., 80, 4591-4597, 1975.

Mantas, G. P., and C. G. Walker, The penetration of soft electrons into the ionosphere, Planet. Space Sci., 24, 409-423, 1976.

Marov, M. J., and A. V. Kolesnichenko, Introduction into aeronomy of planets, (in Russian), Nauka, Moscow, 1987.

McFarland, M., D. L. Albritton, F. C. Fehsenfeld, E. E. Ferguson, and A. L. Schmeltekopf, Flow-drift technique for ion mobility and ion-molecule reaction rate constant measurements, II. Positive ion reaction of $\mathrm{N}^{+}, \mathrm{O}^{+}$, and $\mathrm{N}_{2}^{+}$with $\mathrm{O}_{2}$ and $\mathrm{O}^{+}$with $\mathrm{N}_{2}$ from thermal to $2 \mathrm{eV}$, J. Chem. Phys., 59, 6620- 6628, 1973.

Newton, G. P., and J. C. G. Walker, Electron density decrease in SAR arcs resulting from vibrationally excited nitrogen, $J$. Geophys. Res., 80, 1325-1327, 1975.

Newton, G. P., J. C. G. Walker, and P. H. E. Meijer, Vibrationally excited nitrogen in stable auroral red arcs and its effect on ionospheric recombination, J. Geophys. Res., 79, 3807-3818, 1974.

Pavlov, A. V., On the $\mathrm{O}_{2}^{*}$ content in the upper atmosphere and the effect of $\mathrm{N}_{2}^{*}$ and $\mathrm{O}_{2}^{*}$ on the electron density (in Russian), Geomagn. Aeron., 29, 818-823, 1989a.

Pavlov, A. V., About the role of vibrationally excited nitrogen in the sabauroral red arc region (in Russian), Geomagn. Aeron., 29, 948-953, 1989b.

Pavlov, A. V., Mechanisms of the electron density depletion in the SAR arc region, Ann. Geophysicae, 14, 211-221, 1996.

Pavlov, A. V., Subauroral red arcs as a conjugate phenomenon: comparison of OV1-10 satellite data with numerical calculations, Ann. Geophysicae, 15, 984-998, 1997.

Pavlov, A. V., New electron energy transfer rates for vibrational excitation of $\mathrm{N}_{2}$, Ann. Geophysicae, 16, 176-182, 1998a.

Pavlov, A. V., The role of vibrationally excited oxygen and nitrogen in the ionosphere during the undisturbed and geomagnetic storm period of 6-12 April 1990, Ann. Geophysicae, 16, 589601, 1998b.

Pavlov, A. V., New electron energy transfer and cooling rates by excitation of $\mathrm{O}_{2}$, Ann. Geophysicae, 16, 1007-1013, 1998c.

Pavlov, A. V., and A. A. Namgaladze, Vibrationally excited nitrogen in the upper atmosphere. Review paper (in Russian), Geomagn. Aeron., 28, 705-721, 1988.

Pavlov, A. V., and M. J. Buonsanto, Comparison of model electron densities and temperatures with Millstone Hill observations during undistributed periods and the geomagnetic storms of March 16-23 and April 6-12, 1990, Ann. Geophysicae, 15, 327344, 1997.

Pavlov, A. V., and K. A. Berrington, Cooling rate of thermal electrons by electron impact excitation of fine structure levels of atomic oxygen, Ann. Geophysicae, 17, 1999 (in press).

Piper, L. G., The excitation of $\mathrm{O}\left({ }^{1} \mathrm{~S}\right)$ in the reaction between $\mathrm{N}_{2}\left(\mathrm{~A}^{3} \Sigma_{\mathrm{u}}^{+}\right)$and $\mathrm{O}\left({ }^{3} \mathrm{P}\right)$, J. Chem. Phys., 77, 2372-2381, 1981.

Piper, L. G., Reevaluation of the transition- moment function and Einstein coefficients for the $\mathrm{N}_{2}\left(\mathrm{~A}^{3} \Sigma_{\mathrm{u}}^{+}-\mathrm{X}^{1} \Sigma_{\mathrm{g}}^{+}\right)$transition, J. Chem. Phys., 99, 3174-3181, 1993.

Prasad, S. S., and D. R. Furman, Electron cooling by molecular oxygen, J. Geophys. Res., 78, 6701-6707, 1973.

Prasad, J. S., J. S. Kim, and S. Okano, Observations of soft electron flux during SAR arc event, Planet. Space. Sci., 28, 375379, 1980.

Radzig, A. A., and B. V. Smirnov, The reference book in atomic and molecular physics (in Russian), Atomizdat, Moscow, 1980.

Raitt, W. J., Schunk R. W., and P. M. Banks, Ionospheric composition in SAR-arcs, Planet. Space Sci., 24, 105-114, 1976.

Reed, E. I. and J. E. Blamont, Ogo 4 observations of the September 1967 M-arc, EOS Trans. AGU, 49, 731, 1968.

Rees, M. H. and R. G. Roble, Observations and theory of the formation of stable auroral red arcs. Rev. Geophys. Space Phys., 13, 201-242, 1975. 
Roble, R. G., and M. H. Rees, Time-dependent studies of the aurora: effects of particle precipitation on the dynamic morphology of ionospheric and atmospheric properties, Planet. Space Sci., 25, 991-1010, 1977.

Richards, P. G., An improved algorithm for determining neutral winds from the height of the F2 peak electron density, J. Geophys. Res., 96,17 839-17 846, 1991.

Richards, P. G., J. A. Fennelly, and D. G. Torr, EUVAC: a solar EUV flux model for aeronomical calculations, J. Geophys. Res., 99, 8981-8992, 1994. (Correction in J. Geophys. Res., 99, 13 283, 1994).

Robertson, A. G., M. T. Elford, R. W. Crompton, M. A. Morrison, W. Sun, and W.K. Trail, Rotational and vibrational excitation of nitrogen by electron impact, Aust. J. Phys., 50, 441-472, 1997.

Schmeltekopf, A. L., E. E. Ferguson, and F. C. Fehsenfeld, Afterglow studies of the reactions $\mathrm{He}^{+}, \mathrm{He}\left(2^{3} \mathrm{~S}\right)$, and $\mathrm{O}^{+}$with vibrationally excited $\mathrm{N}_{2}, J$. Chem. Phys., 48, 2966-2973, 1968.

Schulz, G. J., A review of vibrational excitation of molecules by electron impact at low energies, in Principles of laser plasmas, Ed. G. Berkefi. Interscience, New York, 1976, p. 33-76.

Schunk, R. W., and A. F. Nagy, Electron temperatures in the F region of the ionosphere: Theory and observations, Rev. Geophys. Space Phys., 16, 355-399, 1978.

Shepherd, G. G., L. H. Brace, J. R. Burrows, J. H. Hoomann, H. G. James, D. M. Klumpar, A. F. Nagy, E. Stathopoulos, and J. H. Whitteker, An unusual SAR arc observed during ring current development, 4 August, 1972, Planet. Space Sci., 28, 69-84, 1980.

Singh, V., I. C. McDade, G. G. Shepherd, B. H. Solheim, W. E. Ward, The $\mathrm{O}\left({ }^{1} \mathrm{~S}\right)$ dayglow emission as observed by the WIND imaging interferometer on the UAR, Ann. Geophysicae, 14, $637-$ 646, 1996.

Singhal, R. P., and A. E. S. Green, Spatial aspects of electron energy degradation in atomic oxygen, J. Geophys. Res., 86, 4776-4780, 1981.

Singhal, R. P., C. H. Jackman, and A. E. S. Green, Spatial aspects of low- and medium-energy electron degradation in $\mathrm{N}_{2}$, J. Geophys. Res., 85, 1246-1254, 1979.

Slanger, T. G., and G. Black, $\mathrm{O}\left({ }^{1} S\right)$ quenching by $\mathrm{O}\left({ }^{3} P\right)$, J. Chem. Phys., 64, 3763-3773, 1976.

Slanger, T. G., B. J. Wood, and G. Black, The temperature dependence of $\mathrm{O}\left({ }^{1} \mathrm{~S}\right)$ quenching by $\mathrm{O}_{2}$, Chem. Phys. Lett., 17, 401-403, 1972.

Slater, D. W., C. Gurgiolo, J. U. Kozyra, E. W. Kleckner, and J. D. Winningham, A possible energy source to power stable auroral red arcs: precipitating electrons, J. Geophys. Res., 92, 45434552, 1987.

Stubbe, P., and W. S. Varnum, Electron energy transfer rates in the ionosphere, Planet. Space Sci., 20, 1121-1126, 1972.

Thomas, L. D. and R. K. Nisbet, Low-energy electron scattering by atomic oxygen, Phys. Rev., 11, 170-173, 1975.

Thomas, J. M., and F. Kaufman, Rate constant of the reactions of metastable $\mathrm{N}_{2}\left(\mathrm{~A}^{3} \Sigma_{\mathrm{u}}^{+}\right)$in $\mathrm{v}=0,1,2$ and 3 with the ground state $\mathrm{O}$ and $\mathrm{O}_{2}$, J. Chem. Phys., 83, 2900-2903, 1985.

Titheridge, J. E., Model results for the ionospheric E region: solar and seasonal changes, Ann. Geophysicae, 15, 63-78, 1997.

Torr, M. R., and D. G. Torr, The role of metastable species in the thermosphere, Rev. Geophys. Space Phys., 20, 91-144, 1982.

Williams, J. F., and L. J. Allen, Low-energy elastic scattering of electrons from atomic oxygen, J. Phys. B: At. Mol. Opt. Phys., 22, 3529-3539, 1989. 